\title{
Aplicaciones biotecnológicas de los microorganismos
}

\author{
Biotechnological applications of microorganisms
}

Olga Lucía Ostos Ortíz ${ }^{1}$, Sonia Marcela Rosas Arango ${ }^{1}$, Johanna Lizeth González Devia ${ }^{1}$

\section{Resumen}

La biodiversidad de los microorganismos así como la naturaleza única y las capacidades biosintéticas en condiciones ambientales específicas hacen que los microorganismos sean los probables candidatos para resolver problemas de escases de alimentos, contro de plagas, biodegradación de los xenobióticos, descomposición de la basura, las pilas de desechos producidas, entre otros.

Los microorganismos ofrecen un gran potencial para la exploración de moléculas y procesos, y el conocimiento de las especies no convencionales, especialmente dentro del grupo Archaea, ha estimulado la investigación molecular de genes de interés. Estos nuevos genes pueden incorporarse mediante tecnología recombinante en especies biológicamente conocidas, como E. coli y S. cerevisiae, para la síntesis a gran escala de productos.

La microbiología tecnológica tiene grandes potenciales para explorar y obstáculos por superar. Por lo tanto, solo la investigación en esta área resulta prometedora para científicos en todo el mundo.

En la presente revisión se presentan las aplicaciones más significativas de los microorganismos en la industria de alimentos, la agricultura, compuestos químicos, combustibles, farmacología y materiales.

Palabras claves: biotecnología, microbiología de alimentos, biocombustibles, vacunas, biopolímeros, biosensores, microbiología ambiental, biofábricas.

1. Unidad de Investigación Universidad Santo Tomás

Bogotá, Colombia.

ORCID OL00: https://orcid.org/0000-0002-6477-9872

ORCID SMRA: https://orcid.org/0000-0002-4798-1753

ORCID JLGD: https://orcid.org/0000-0003-4162-6678 


\section{Abstract}

The biodiversity of microorganisms as well as the unique nature and biosynthetic capabilities in specific environmental conditions make microorganisms the likely candidates to solve problems of food shortages, pest control, biodegradation of xenobiotics, decomposition of garbage, batteries of produced waste, among others.

Microorganisms offer great potential for the exploration of molecules and processes, and knowledge of non-conventional species, especially within the Archaea group, has stimulated the molecular investigation of genes of interest. These new genes can be incorporated by recombinant technology into biologically known species, such as E. coli and S. cerevisiae, for the large-scale synthesis of products.

Technological microbiology has great potentials to explore and obstacles to overcome. Therefore, only research in this area is promising for scientists around the world.

In this review we present the most significant applications of microorganisms in the food industry, agriculture, chemical compounds, fuels, pharmacology and materials.

Keywords: biotechnology, food microbiology, biofuels, vaccines, biopolymers, biosensors, environmental microbiology, biofactories.

\section{Introducción}

A través de la historia las aplicaciones biotecnológicas de los microorganismos han sido documentadas (1-8), tabla 1 .

Tabla 1. Aplicaciones biotecnológicas de microorganismos en la historia de la humanidad.

\begin{tabular}{|c|c|c|c|}
\hline Aplicación & Zona geográfica & Año & Bibliografia \\
\hline $\begin{array}{c}\text { Fermentación de granos de cereales para producir una } \\
\text { bebida alcohólica }\end{array}$ & $\begin{array}{c}\text { Aldea neolítica de Jiahu en } \\
\text { China }\end{array}$ & $\begin{array}{c}\text { McGovern et } \\
\text { al.,2004 (2) }\end{array}$ \\
\hline $\begin{array}{c}\text { Fermentación de granos de cereales para producir una } \\
\text { bebida alcohólica }\end{array}$ & $\begin{array}{c}\text { Montańas Zagros del norte de } \\
\text { Mesopotamia. }\end{array}$ & $5400-5000 \mathrm{aC}$ & $\begin{array}{c}\text { McGovern et al., } \\
2004(2)\end{array}$ \\
\hline $\begin{array}{c}\text { Indicio de la producción de vino } \\
\text { Indicio de la producción de vino }\end{array}$ & Depe en Mesopotamia & $5400-5000 \mathrm{aC}$ & $\begin{array}{c}\text { McGovern et al., } \\
1996(2)\end{array}$ \\
\hline Producción a gran escala de vino & China, Mesopotamia y Grecia & $5000 \mathrm{a}$. C. & $\begin{array}{c}\text { Valamoti et al., 2007 } \\
(3)\end{array}$ \\
\hline Producción de pan con levadura & Egipto & 2013 (4) \\
\hline
\end{tabular}




\begin{tabular}{|c|c|c|c|}
\hline Aplicación & Zona geográfica & Año & Bibliografia \\
\hline Prácticas de fermentación & $\begin{array}{l}\text { Asia, Mesopotamia, Egipto y } \\
\text { Viejo mundo }\end{array}$ & & $\begin{array}{l}\text { Sicard y Legras, } \\
2011(6)\end{array}$ \\
\hline Producción de alcohol a base de remolacha & $\begin{array}{l}\text { Región agrícola-industrial de } \\
\text { Lille }\end{array}$ & 1857 & Gal, $2008(7)$ \\
\hline $\begin{array}{l}\text { Asociación de microorganismos con enfermedades y } \\
\text { proponiendo métodos de vacunación como los utilizados } \\
\text { contra el ántrax (1881) y la rabia humana (1885) }\end{array}$ & Pouilly-le-Fort, Francia & 1857 & $\begin{array}{l}\text { Gal, } 2008(7) \\
\text { Pasteur, } 2002(8) \\
\text { Plotkin y Plotkin, } \\
\text { 2011(9) }\end{array}$ \\
\hline Uso del glicerol para la fabricación de explosivos & China & $\begin{array}{c}\text { Primera Guerra } \\
\text { Mundial }\end{array}$ & $\begin{array}{l}\text { Wang et al., } 2001 \\
\text { (10) }\end{array}$ \\
\hline Producción a gran escala de penicilina por Fleming & Londres, Reino Unido & década de 1940 & Neushul, 1993 (11) \\
\hline $\begin{array}{l}\text { Desarrollo de procesos industriales basados en } \\
\text { microorganismos }\end{array}$ & Francia & $\begin{array}{l}\text { Final de la } \\
\text { Segunda Guerra } \\
\text { Mundial }\end{array}$ & $\begin{array}{l}\text { Jacob et al., } 1960 \\
\text { (12); Ames y } \\
\text { Martin, } 1964(13) ; \\
\text { Holloway, } 1969( \\
14)\end{array}$ \\
\hline $\begin{array}{c}\text { Obtencion de una patente (Ananda Chakrabarty) apartir } \\
\text { de una variante de Pseudomonas putida que es eficaz en } \\
\text { la digestión de compuestos encontrados en derrames de } \\
\text { petróleo crudo }\end{array}$ & Dordrecht, Países Bajos & Decada de 1980 & Holloway, 2014 (15) \\
\hline $\begin{array}{l}\text { Analisis de endonucleasas bacterianas que hidrolizan el } \\
\text { ADN de los virus que invaden estos microorganismos }\end{array}$ & Ginebra, Suiza & $\begin{array}{l}\text { Principios de la } \\
\text { década de } 1970\end{array}$ & $\begin{array}{l}\text { Smith y Nathans, } \\
1973 \text { (16) ; Arber, } \\
1974(17)\end{array}$ \\
\hline $\begin{array}{l}\text { Modificación genética de Escherichia coli para } \\
\text { producción de insulina artificial }\end{array}$ & Limerick, Irlanda & década de 1970 & Walsh, 2012 (18) \\
\hline $\begin{array}{l}\text { Construcción de células de E. coli quiméricas } \\
\text { conteniendo ADN de Xenopus laevis }\end{array}$ & California, EE. UU. & Decada de 1970 & $\begin{array}{l}\text { Cohen et al., } 1973 \\
\text { (19) ; Berg y Mertz, } \\
2010(20)\end{array}$ \\
\hline
\end{tabular}




\begin{tabular}{|c|c|c|c|}
\hline Aplicación & Zona geográfica & Año & Bibliografia \\
\hline $\begin{array}{c}\text { Aislamiento de una ADN polimerasa termoestable de la } \\
\text { bacteria Thermus aquaticus: Reacción en cadena de la } \\
\text { polimerasa (PCR) }\end{array}$ & California, EE. UU. & 1976 & $\begin{array}{l}\text { Chien et al., } 1976 \\
\text { (21); Saiki et al., } \\
1988(22)\end{array}$ \\
\hline Manipulación genética de microorganismos & Francia & $\begin{array}{l}\text { A partir de la } \\
\text { década de } 1980\end{array}$ & $\begin{array}{l}\text { Simon y Chopin, } \\
1988(23) \text {; Olsen, } \\
2016(24)\end{array}$ \\
\hline Descrubrimiento de Archeas a partir de $16 \mathrm{~S}$ rRNA & Estados Unidos & década de 1970 & $\begin{array}{l}\text { Woese y Fox, } 1977 \\
(25) \text {; Woese et al., } \\
1990(26)\end{array}$ \\
\hline $\begin{array}{l}\text { Las bacterias RCP tienen genomas pequeños y } \\
\text { composiciones ribosómicas inusuales, además de carecer } \\
\text { de numerosas vías biosintéticas }\end{array}$ & California, EE. UU. & 2015 & $\begin{array}{l}\text { Brown et al., } 2015 \\
\text { (27) }\end{array}$ \\
\hline $\begin{array}{l}\text { Las bacterias DPANN se ha definido como una función } \\
\text { de la capacidad metabólica }\end{array}$ & California, EE. UU. & 2015 & $\begin{array}{l}\text { Rinke et al., } \\
\text { 2013(28) ; Castelle } \\
\text { et al., } 2015 \text { (29) }\end{array}$ \\
\hline $\begin{array}{l}\text { Descubrimiento del grupo bacteriano Candidate Phyla } \\
\text { Radiation (CPR) y Archaea superphylum DPANN }\end{array}$ & Uppsala, Suecia & 2016 & $\begin{array}{l}\text { (Spang and Ettema, } \\
2016(30)\end{array}$ \\
\hline $\begin{array}{c}\text { Descubrimiento del papel biotecnológico de muchas } \\
\text { arqueas, como Halobacterium, Pyrococcus y } \\
\text { Thermococcus }\end{array}$ & Estados Unidos & 2016 & $\begin{array}{l}\text { Coker, } 2016(31) \text {; } \\
\text { Waditee-Sirisattha et } \\
\quad \text { al., } 2016(32)\end{array}$ \\
\hline $\begin{array}{l}\text { Descubrimiento de PGPMs, microorganismos } \\
\text { promotores del crecimiento vegetal. }\end{array}$ & Estados Unidos & 2016 & $\begin{array}{l}\text { Coker, } 2016(31) \text {; } \\
\text { Waditee-Sirisattha et } \\
\quad \text { al., } 2016(32)\end{array}$ \\
\hline
\end{tabular}

\section{Microorganismos en la industria de alimentos}

La humanidad enfrenta un crecimiento poblacional que tiene como consecuencia un aumento de la demanda alimentos en todo el mundo.

La posibilidad de utilizar microorganismos para obtener alimentos, aditivos alimentarios o incluso biomasa microbiana ha generado nuevas posibilidades, desde la generación de nuevos sabores, texturas y aromas, hasta el descubrimiento de nuevos alimentos.

La aplicación de técnicas biotecnológicas en la industria de alimentos se da en la década de 1970. Actualmente se utilizan microorganismos modificados genéticamente, enzimas, colorantes y otros compuestos obtenidos con 
el objetivo de mejorar sus características organolépticas, funciones nutricionales, productividad, entre otros.

Los microorganismos pueden tener dos funciones diferentes en la producción actual de alimentos: (1) Iniciadores en las fermentaciones, en los que no se utilizan microorganismos modificados genéticamente, (2) Fabricación de ingredientes en la industria alimentaria, se utilizan microorganismos modificados genéticamente y la participación en procesos de fermentación se hace mediante uso de metabolitos o aditivos (participación indirecta).

Se han dado importantes descubrimientos en este tema. Anupama y Ravindra, 2000 (33) informan la proteína unicelular - SCP, proteína extraída de la biomasa microbiana cultivada que se puede usar para la suplementación de proteínas en dietas básicas, reemplazando las fuentes convencionales y aliviando el problema de la escasez de proteínas.

Adedayo et al., 2011 (34) documentan como el SCP se ha utilizado ampliamente como fuente de proteínas en alimentos para animales y humanos. Las levaduras más utilizadas para obtener SCP son: Saccharomyces, Candida y Rhodotorula. Cepas bacterianas de Bacillus, Hydrogenomonas, Methanomonas, Methylomonas, y Pseudomonasse han utilizado como sustrato para la producción de $S$ a escala industrial porque estas bacterias pueden contener aproximadamente un $80 \%$ de proteína cruda en el peso seco total.

Los hongos filamentosos para la producción de $S$ más utilizados son Fusarium, Aspergillus y Penicillium, y entre las algas procarióticas, las más utilizadas pertenecen al género Spirulina., con aproximadamente el 65\% de su peso seco consistente en proteínas (35). Sin embargo, el cultivo de levaduras es más práctico porque estos microorganismos pueden usar una amplia variedad de sustratos (36); aunque que los SCP obtenidos son insuficientes en aminoácidos que contienen azufre.

Linko y col 1997 (37) informan el uso de la ingeniería genética para modificar las propiedades la levadura natural, mejorando su rendimiento en el proceso de fermentación en variedad de sustratos., mediante variaciones de temperatura y $\mathrm{pH}$.

Takagi y Shima, 2015 (38) informan compuestos implicados en la tolerancia al estrés en levaduras, como la prolina y la trehalosa. Dichos mecanismos han generado que las levaduras sean sometidas a nuevos procesos, como la radiación UV. De la misma forma, Degré et al., 2008; Lipkie et al., 2016 (3940) han desarrollado alimentos con nuevos atributos nutricionales, como los alimentos con niveles elevados de vitamina D.

En la actualidad se utilizan cepas que no son de Saccharomyces, en el proceso de vinificación para aumentar su complejidad organoléptica, aprovechando la capacidad de las cepas para producir enzimas, metabolitos secundarios: glicerol, etanol y otros compuestos (Padilla et al., 2016 ) (41).

Sauer et al., 2008(42) analizan como la mayoría de los ácidos orgánicos: ácido acético, cítrico, láctico y succínico, son útiles como materias primas para la industria química o alimentaria. 
Las levaduras productoras de $\beta$-liasas mejoran la liberación de tiol aromático y, en consecuencia, las propiedades sensoriales de los vinos (43), mientras que la selección de levaduras especializadas en ciertos procesos como la floculación puede mejorar la fermentación de vinos especiales, como vinos espumosos (44).

Satish et al., 2013 (45); Mokoena et al., 2016 (46) informan nuevas fuentes de probióticos y el descubrimiento de cepas que pueden mejorar la calidad de los productos fermentados. La industria de los probióticos ha tenido un crecimiento significativo gracias a los estudios en microorganismos de los generos Lactobacillus y Bifidobacterium (47). Dichos microorganismos se han vinculado como generadores de beneficios para la salud del huésped (48). Enujiugha y Badejo, 2017 (49) informan variedades emergentes de bebidas probióticas no lácteas.

\section{El procesamiento de alimentos utiliza prepa- raciones enzimáticas de origen microbiano que se presentan en la Tabla 2 .}

Tabla 2. Preparaciones enzimáticas a partir de microorganismos y su utilidad.

\begin{tabular}{|c|c|c|c|}
\hline Preparación enzimática & Microorganismo de origen & Utilidad & Documentado por \\
\hline Amilasas & Aspergillus niger, Bacillus subtilis & $\begin{array}{c}\text { Mejora en la preparación de la } \\
\text { masa para hornear. y permite } \\
\text { la adquisición de alimentos } \\
\text { precocinados. }\end{array}$ & $\begin{array}{c}\text { Omemu et al., } 2005 \text { (50) ; Djekrif- } \\
\text { Dakhmouche et al., } 2006 \text { (51); } \\
\text { Adejuwon et al., } 2015 \text { (52); Ploss et } \\
\text { al., } 2016 \text { (53); Salman et al. , } 2016 \\
\text { (54). }\end{array}$ \\
\hline $\begin{array}{l}\text { Producción de lipasas } \\
\text { extracelulares }\end{array}$ & A. niger y Rhizomucor miehei & $\begin{array}{l}\text { Facilitan la recuperación de } \\
\text { enzimas. Hidrólisis de la } \\
\text { grasa de la leche, mejorando } \\
\text { la aromatización de los } \\
\text { productos lácteos }\end{array}$ & $\begin{array}{l}\text { Rodrigues y Fernández-Lafuente, } \\
2010 \text { (55); Messias et al., } 2011 \text { (56) }\end{array}$ \\
\hline $\begin{array}{l}\text { Producción de lipasas } \\
\text { extracelulares }\end{array}$ & A. niger y Rhizomucor miehei & $\begin{array}{l}\text { Mejoramiento del aroma de } \\
\text { las bebidas y la calidad de la } \\
\text { margarina y la mayonesa }\end{array}$ & Sharma et al., 2001 (57) \\
\hline $\begin{array}{l}\text { Producción de celulasas y } \\
\text { pectinasas }\end{array}$ & $\begin{array}{l}\text { Cultivos de hongos } \\
\text { filamentosos: Cladosporium } \\
\text { Sphaerospermum, Penicillium } \\
\text { chrysogenum y Trichoderma } \\
\text { viride }\end{array}$ & $\begin{array}{c}\text { Clarificación de jugos y la } \\
\text { reducción de la viscosidad. } \\
\text { Degradación de la biomasa } \\
\text { vegetal }\end{array}$ & $\begin{array}{l}\text { Andersen et al., 2016) (58) } \\
\text { Ismail et al., } 2016 \text { (59) }\end{array}$ \\
\hline $\begin{array}{l}\text { Inmovilización de celulasas } \\
\text { y pectinasas enzimas en } \\
\text { soportes prefabricados o } \\
\text { matrices de polímeros }\end{array}$ & Hongos filamentosos & Uso en reactores industriales & $\begin{array}{l}\text { Mateo et al., 2007(60); Sheldon, } \\
\qquad 2007(61)\end{array}$ \\
\hline $\begin{array}{c}\text { Aromas naturales y aromas } \\
\text { para alimentos }\end{array}$ & $\begin{array}{l}\text { A. niger y Pycnoporus } \\
\text { cinnabarinus }\end{array}$ & $\begin{array}{l}\text { Cosméticos, jabones, velas y } \\
\text { alimentos }\end{array}$ & Carroll et al., 2016 (62) \\
\hline Síntesis de vainillina & $\begin{array}{l}\text { A. niger y Pycnoporus } \\
\text { cinnabarinus }\end{array}$ & $\begin{array}{l}\text { Saborizante de alimentos, } \\
\text { a partir de salvado de maíz } \\
\text { autoclavado }\end{array}$ & Lesage-Meessen et al. (63) \\
\hline
\end{tabular}




\begin{tabular}{|c|c|c|c|}
\hline Preparación enzimática & Microorganismo de origen & Utilidad & Documentado por \\
\hline Fermentación del café & levaduras del género Pichia & $\begin{array}{c}\text { Mejorar la calidad y el sabor } \\
\text { de la bebida, ya que aumentan } \\
\text { la producción del acetato de } \\
\text { isoamilo de sabor natural }\end{array}$ & Saerens y Swiegers, 2016 (64) \\
\hline Síntesis de acetoína & E. coli & $\begin{array}{c}\text { Convertir enzimáticamente } \\
\text { precursores baratos, como } \\
\text { la glucosa o el glicerol, en } \\
\text { compuestos aromáticos } \\
\text { costosos. }\end{array}$ & Nielsen et al., 2010 (65). \\
\hline
\end{tabular}

\section{Microorganismos con utilidad en agroindustria}

En los últimos años, se ha logrado mucho progreso en el desarrollo y comercialización de bionematicidas (66). El interés en los microorganismos se ha centrado en compuestos con actividad pesticida, principalmente herbicidas, insecticidas y nematicidas. Especies como Trichoderma y otras especies de biocontrol responden a la creciente demanda de prácticas que minimicen los efectos secundarios que dejan los pesticidas, como la resistencia en las poblaciones de plagas, la reducción de la calidad del suelo y del agua y la generación de residuos con efectos nocivos en organismos no objetivo. Tabla 3.

Tabla 3. Aplicaciones biotecnológicas de microorganismos con utilidad en la agroindustria.

\begin{tabular}{|c|c|c|}
\hline Microorganismos & Efecto & Autor \\
\hline $\begin{array}{c}\text { Phytophthora palmivora: Suspensión de } \\
\text { clamidiosporas }\end{array}$ & Controlar Morrenia odorata & McRae, 1988 (67) \\
\hline $\begin{array}{c}\text { Colletotrichum gloeosporioides (Penz) } \\
\text { Sacc. F. sp. Aeschynomene }\end{array}$ & $\begin{array}{c}\text { Induce síntomas de antracnosis en } \\
\text { Aeschynomene virginica }\end{array}$ & McRae, 1988 (67) \\
\hline $\begin{array}{c}\text { Puccinia canaliculata } \\
\text { Controlar el espigamiento amarillo } \\
\text { Cyperus esculentus L inhibiendo } \\
\text { completamente la floración y } \\
\text { reduciendo la formación de tubérculos }\end{array}$ & Duke et al., 2015 (68) \\
\hline $\begin{array}{c}\text { B. thuringiensis (Bt): producen } \\
\text { endotoxinas Cry y Cyt }\end{array}$ & $\begin{array}{c}\text { Acción entomopatógena, controlando } \\
\text { las plagas presentes en la col, la papa y } \\
\text { los granos. }\end{array}$ & Sarwar, 2015a (69) \\
\hline $\begin{array}{c}\text { Especies transgénicas que expresan } \\
\text { cristales de proteína Bt, como el } \\
\text { tomate, el tabaco y el maíz }\end{array}$ & $\begin{array}{c}\text { Prevención de la propagación de las } \\
\text { orugas, especialmente los lepidópteros }\end{array}$ & Khan et al., 2016 (70) \\
\hline
\end{tabular}




\begin{tabular}{|c|c|c|}
\hline Microorganismos & Efecto & Autor \\
\hline $\begin{array}{l}\text { Baculovirus infectando orugas y } \\
\text { huevos de plagas como Spodoptera } \\
\text { frugiperda }\end{array}$ & $\begin{array}{c}\text { Redución de las pérdidas agrícolas } \\
\text { causadas por esta oruga, especialmente } \\
\text { en el maíz. }\end{array}$ & Popham et al., 2016 (71) \\
\hline $\begin{array}{l}\text { Hongos patógenos de insectos: } \\
\text { Beauveria, Metarhizium y Paecilomyces }\end{array}$ & $\begin{array}{l}\text { Estos se utilizan con mayor frecuencia } \\
\text { contra las orugas foliares en } \\
\text { invernaderos u otros lugares donde la } \\
\text { humedad es relativamente alta }\end{array}$ & Sarwar, 2015b (72) \\
\hline $\begin{array}{c}\text { Productos de la bacteria Streptomyces } \\
\text { avermitilis conocidos como } \\
\text { avermectinas }\end{array}$ & $\begin{array}{l}\text { Pesticidas modelo, no tóxicos para } \\
\text { los mamíferos y activos contra los } \\
\text { nematodos, incluso en dosis muy } \\
\text { bajas. }\end{array}$ & Sarwar, 2015b (72) \\
\hline B. firmus & $\begin{array}{l}\text { Inducen parálisis y mortalidad } \\
\text { de nematodos y larvas adultos, } \\
\text { incluyendo Radopholus similis, } \\
\text { Meloidogyne incognita y Ditylenchus } \\
\text { dipsaci, lo que sugiere la síntesis de } \\
\text { metabolitos tóxicos }\end{array}$ & Mendoza et al., 2008 (73) \\
\hline Myrothecium verrucaria & $\begin{array}{l}\text { Produce metabolitos tóxicos (inhiben } \\
\text { el desarrollo y eclosión de huevos) } \\
\text { cuando se cultivan en biorreactores. }\end{array}$ & Twomey et al., 2000 (74) \\
\hline Pasteuria sp & $\begin{array}{l}\text { Utilizar el parasitismo como método } \\
\text { de control. }\end{array}$ & Davies et al., 2011 (75) \\
\hline Hongos del género Trichoderma & Control biológico de las plagas & 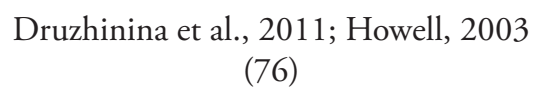 \\
\hline Trichoderma spp & $\begin{array}{c}\text { Parasitar y controlar con éxito especies } \\
\text { de hongos fitopatógenos como } \\
\text { Sclerotinia, Fusarium, Verticillium y } \\
\text { Macrophomina }\end{array}$ & $\begin{array}{l}\text { Jones et al., 2014(77), } 2016(78) \text {; } \\
\text { Saravanakumar et al., } 2016(79) ; \\
\text { Carrero-Carron et al., } 2016(80) ; \\
\text { Khaledi y Taheri, } 2016(81)\end{array}$ \\
\hline Trichoderma spp & $\begin{array}{l}\text { Efecto nematicida en la vesícula } \\
\text { formación de Meloidogyne }\end{array}$ & $\begin{array}{c}\text { Sahebani y Hadavi, } 2008 \text { (82) ; Feyisa } \\
\text { et al., } 2016(83) \text {; Sokhandani et al., } \\
2016(84)\end{array}$ \\
\hline
\end{tabular}




\begin{tabular}{|c|c|c|}
\hline Microorganismos & Efecto & Autor \\
\hline $\begin{array}{c}\text { Microorganismos simbióticos: como } \\
\text { los hongos micorriza y las rizobacterias }\end{array}$ & $\begin{array}{c}\text { Desarrollan actividades que pueden } \\
\text { mejorar la condición física de la } \\
\text { planta, facilitando la adquisición de } \\
\text { nutrientes. }\end{array}$ & $\begin{array}{c}\text { Cheng et al., 2016 (21) } \\
\text { Walder et al., 2016 (85) }\end{array}$ \\
\hline $\begin{array}{c}\text { PGPR (rizobacterias promotoras a través de mecanismos } \\
\text { crecimiento de las plantas) }\end{array}$ & $\begin{array}{c}\text { Actectos: biofertilización, síntesis } \\
\text { de auxinas,citoquinas y giberelinas } \\
\text { e indirectos: antibiosis, resistencia } \\
\text { sistémica, competencia por nutrientes, } \\
\text { promueven el crecimiento de las } \\
\text { plantas. }\end{array}$ & Lugtenberg y Kamilova, 2009 (86) \\
\hline
\end{tabular}

\section{Microorganismos en la industria química}

Los productos de desecho se convierten en sustratos susceptibles a la acción microbiana (87) con el interés de resolver los problemas ambientales que generan el uso de combustibles fosiles y las ventajas que trae el uso de materias primas renovables (88).

\section{Microorganismos y biocombustibles}

La síntesis de químicos a través de procesos metabólicos microbianos reduce la dependencia de los combustibles fósiles para la generación de energía.
A futuro se espera que al menos el $25 \%$ de toda la bioenergía pueda provenir del biogás (89). Numerosos estudios buscan optimizar el proceso de metanogénesis mediante técnicas de secuenciación de próxima generación (NGS) ayudarán a conocer la estructura de las comunidades microbianas (90-93).

Los aislamientos que se han logrado son una fuente de nuevos productos y servicios en el futuro (94).

Tabla 4. Microorganismos y biocombustibles. Se presentan los productos y servicios, anotaciones clave y la bibliografía donde se reporta.

\begin{tabular}{|c|c|c|}
\hline Producto y servicios & Anotaciones & Bibliografia \\
\hline $\begin{array}{l}\text { Producción de etanol de segunda } \\
\text { generación obtenida de biomasa } \\
\text { lignocelulósica }\end{array}$ & $\begin{array}{l}\text { Se necesitan mejoras para que la } \\
\text { tecnología sea económicamente } \\
\text { competitiva. } \\
\text { Se ha identificado tolerancia al ácido } \\
\text { acético (inhibidores de los hidrolizados } \\
\text { de lignocelulosa) }\end{array}$ & $\begin{array}{c}\text { Liao et al., } 2016 \text { (95) } \\
\text { Meijnen et al., } 2016 \text { (96) }\end{array}$ \\
\hline Biodegradación de crudos & Pseudomona spp & Ostos, et al (97) \\
\hline
\end{tabular}




\begin{tabular}{|c|c|c|}
\hline Producto y servicios & Anotaciones & Bibliografia \\
\hline $\begin{array}{l}\text { Descubrimiento de las isomerasas } \\
\text { funcionales de xilosa }\end{array}$ & $\begin{array}{l}\text { Dieron como resultado la creación de } \\
\text { nuevas levaduras capaces de fermentar } \\
\text { azúcares de } 5 \text { carbonos (C5), así como } \\
\text { azúcares de } 6 \text { carbonos (C6). }\end{array}$ & Kuyper et al., 2005; (98) \\
\hline $\begin{array}{l}\text { Levaduras capaces de fermentar } \\
\text { azúcares de } 5 \text { carbonos (C5), así como } \\
\text { azúcares de } 6 \text { carbonos (C6). }\end{array}$ & $\begin{array}{l}\text { La co-fermentación de azúcares C5 } \\
\text { con jugo de cańa puede producir } \\
\text { hasta un 37\% más de etanol en } \\
\text { fermentadores de primera generación }\end{array}$ & Losordo et al., 2016 (99) \\
\hline $\begin{array}{l}\text { Producción de etanol de segunda } \\
\text { generación. }\end{array}$ & $\begin{array}{l}\text { Mejoras genéticas de la levadura, } \\
\text { prospección de nuevas fuentes de } \\
\text { celulosa, como la silvicultura y los } \\
\text { residuos de cultivos (corteza de } \\
\text { eucalipto, maíz y cáscaras de arroz }\end{array}$ & McIntosh et al., 2016 (100) \\
\hline $\begin{array}{l}\text { Biogás: combinación de metano, } \mathrm{CO} 2 \text {, } \\
\text { nitrógeno, } \mathrm{H} 2 \mathrm{~S} \text {, y trazas de otros gases } \\
\text { producidos por la digestión anaeróbica } \\
\text { (AD) obtenidas de la conversión } \\
\text { microbiana de la biomasa. }\end{array}$ & $\begin{array}{l}\text { El conocimiento sobre los consorcios } \\
\text { microbianos involucrados en este } \\
\text { proceso es limitado debido a la falta de } \\
\text { datos filogenéticos y metabólicos sobre } \\
\text { estos microorganismos }\end{array}$ & $\begin{array}{c}\text { Appels et al., } 2008 \text { (101); Wirth et al., } \\
2012 \text { (102) ; Chojnacka et al., } 2015 \\
\text { (103) }\end{array}$ \\
\hline Produccion de biogas & $\begin{array}{l}\text { Proteobacterias, cloroflexi, firmicutes, } \\
\text { bacteroidetes, actinobacterias, } \\
\text { bacteroides, acidobacterias y } \\
\text { espiroquetas }\end{array}$ & $\begin{array}{c}\text { Chouari et al., } 2005 \text { (104); Chojnacka } \\
\text { et al., } 2015 \text { (103) }\end{array}$ \\
\hline Produccion de biogas & $\begin{array}{l}\text { Metanogenic Archaea, como } \\
\text { Methanosarcina barkeri, } M \text {. frisius y } \\
\text { Methanobacterium formicicum. } \\
\text { No se conocen los genes que controlan } \\
\text { estos sistemas con alta eficiencia }\end{array}$ & $\begin{array}{l}\text { Satpathy et al., } 2016 \text { (105); Goswami } \\
\text { et al., 2016. (106) }\end{array}$ \\
\hline
\end{tabular}

Tabla 5. Microorganismos y compuestos químicos. Se presentan los compuestos químicos, microorganismos asociasos y la bibliografía donde se reporta.

\begin{tabular}{|c|c|c|}
\hline Compuesto quimico & Microorganismo & Autores \\
\hline $\begin{array}{c}\text { El ácido cítrico: aditivo alimentario } \\
\text { por fermentación de glucosa, melaza } \\
\text { de remolacha, melaza de cańa o } \\
\text { almidón de maíz. }\end{array}$ & A. niger & $\begin{array}{c}\text { Adham, 2002 (107); Ikram-ul et al., } \\
2004(108) \text {; Wang et al., 2016 (109) }\end{array}$ \\
\hline Ácido láctico & $\begin{array}{c}\text { Lactobacillus spp. cultivado en } \\
\text { suero ampliamente utilizados en las } \\
\text { industrias alimentaria, farmacéutica, } \\
\text { de cuero y textil (productos } \\
\text { biodegradables y polilácticos } \\
\text { biocompatibles) }\end{array}$ & $\begin{array}{c}\text { Gao et al., 2011 (110) Hofvendahl y } \\
\text { Hahn-Hägerdal, 2000 (111) }\end{array}$ \\
\hline Ácido láctico & $\begin{array}{c}\text { Rhizopus.sp. en condiciones aeróbicas } \\
\text { en medio rico en glucosa y con } \\
\text { cantidades limitadas de nitrógeno }\end{array}$ & $\begin{array}{c}\text { Papagianni, 2004 (112); Fu et al., } \\
2014(113)\end{array}$ \\
\hline
\end{tabular}




\begin{tabular}{|c|c|c|}
\hline Compuesto quimico & Microorganismo & Autores \\
\hline Acido láctico & $\begin{array}{c}\text { Fermentación de Saccharomyces } \\
\text { cerevisiae en medio a base de glucosa y } \\
\text { jugo de caña }\end{array}$ & $\begin{array}{l}\text { Saitoh et al., } 2005(114) \text {; Valli et al., } \\
2006(115)\end{array}$ \\
\hline $\begin{array}{c}\text { Producción microbiana de acetona y } \\
\text { butanol }\end{array}$ & Género Clostridium & Wang et al., 2001 (10) \\
\hline Fermentación del glicerol & $\begin{array}{c}\text { Bacterias del género Clostridium o } \\
\text { Enterobacteriaceae }\end{array}$ & \\
\hline $\begin{array}{l}\text { Síntesis de } 1,3-\mathrm{DOP} \text { microbiana } \\
\text { para generación de polímeros } \\
\text { biodegradables y para obtener } \\
\text { solventes, películas, adhesivos. } \\
\text { anticongelantes y poliésteres }\end{array}$ & $\begin{array}{l}\text { Microorganismos modificados } \\
\text { genéticamente: Genes de bacterias } \\
\text { patógenas, tales como Citrobacter } \\
\text { freundii y Klebsiella }\end{array}$ & $\begin{array}{c}\text { Biebl et al., } 1999 \text { (116)Przystałowska } \\
\text { et al., } 2015 \text { (117) }\end{array}$ \\
\hline
\end{tabular}

\section{Microbiología Tecnológica Ambiental}

Aunque se han documento un número importante de procesos enzimáticos utilizando enzimas biogegradables para el tratamiento de residuos, se requiere un mayor número de estudios para lograr que las enzimas sean termoestables y resistentes a avariaciones de $\mathrm{pH}$, así como estudios que permitan identificar enzimas aplicables, solo aproximadamente el
2\% de los microorganismos del mundo se han probado como fuentes de enzimas (118).

En el futuro, se espera que herramientas genéticas ayuden a aumentar la síntesis enzimática de microorganismos de interés, mejorando las alternativas para la eliminación de los desechos que históricamente se han acumulado en los suelos y cursos de agua.

Tabla 6. Microorganismos y tecnología ambiental. Se presentan los microorganismos, la utilidad asociada a los procesos de tecnología ambiental y la bibliografía donde se reporta.

\begin{tabular}{|c|c|c|}
\hline Microorganismo & Utilidad & Biliografia \\
\hline $\begin{array}{c}\text { Bacterias aerobias heterotróficas o } \\
\text { autótrofas, actinomicetos, coliformes } \\
\text { fecales y termófilos, así como levaduras } \\
\text { y otros hongos }\end{array}$ & $\begin{array}{c}\text { Procesos de compostaje de desechos } \\
\text { sólidos, la temperatura deterina tipos } \\
\text { microbianos y tasa metabólica. }\end{array}$ & $\begin{array}{c}\text { Beffa et al., 1996(119); Tiquia et al., } \\
2002 \text { (120); Hassen et al., 2001 (121). } \\
\text { Uso directo de enzimas microbianas: } \\
\text { las lipasas }\end{array}$ \\
$\begin{array}{c}\text { Tratamiento de efluentes industriales } \\
\text { que contienen principalmente } \\
\text { triglicéridos }\end{array}$ & $\begin{array}{c}\text { Jamie et al., 2016 (122); Hasan et al., } \\
2006(118) .\end{array}$ \\
\hline
\end{tabular}




\begin{tabular}{|c|c|c|}
\hline Microorganismo & Utilidad & Biliografia \\
\hline $\begin{array}{l}\text { Uso directo de enzimas microbianas: } \\
\text { peroxidasas, fenoloxidasas, } \\
\text { dioxigenasas y compuestos similares a } \\
\text { fenoloxidasas }\end{array}$ & $\begin{array}{l}\text { Eliminación de contaminantes } \\
\text { presentes en las aguas residuales }\end{array}$ & Durán y Esposito, 2000 (123) \\
\hline $\begin{array}{l}\text { Las peroxidasas, polifenol } \\
\text { oxidasas y tirosinasas obtenidas de } \\
\text { microorganismos como P. syringae, } \\
\text { Arthromyces ramosus y Agaricus bisporus }\end{array}$ & $\begin{array}{c}\text { Eliminación de fenoles, bifenoles y } \\
\text { clorofenoles }\end{array}$ & $\begin{array}{l}\text { Tatsumi et al., } 1996(124) \text {; Tong et } \\
\text { al., } 1998 \text { (125) ; Akay et al., } 2002 \\
\text { (126) ; Kampmann et al., } 2014 \text { (127). }\end{array}$ \\
\hline Las lacasas de $P$. cinnabarinus & Degradación del benzopireno & Rama et al., 1998 (128). \\
\hline $\begin{array}{c}\text { Peroxidasas de manganeso de } \\
\text { Phanerochaete chrysosporium, } \\
\text { Nematoloma frowardii y Phlebia radiata }\end{array}$ & $\begin{array}{c}\text { Eliminación de lignina en las aguas } \\
\text { residuales }\end{array}$ & $\begin{array}{c}\text { Hofrichter et al., } 1999(129) \text {; Kunz } \\
\text { et al., } 2001(130)\end{array}$ \\
\hline $\begin{array}{c}\text { Celdas microbianas que usan } \\
\text { electrones donados por sustratos } \\
\text { orgánicos de bajo valor, contenidos en } \\
\text { los desechos (MFC) }\end{array}$ & $\begin{array}{l}\text { Tratamiento de desechos sólidos o } \\
\text { incluso aguas residuales }\end{array}$ & Pendyala et al., 2016 (131) \\
\hline $\begin{array}{l}\text { Biofilm BAC carbono biológicamente } \\
\text { activo (BAC) }\end{array}$ & $\begin{array}{l}\text { Mejorar la purificación del agua } \\
\text { potable: biodegradar las cianotoxinas } \\
\text { y sustancias orgánicas que pueden } \\
\text { cambiar el sabor y el olor del agua } \\
\text { potable }\end{array}$ & $\begin{array}{l}\text { Simpson, } 2008 \text { (132); Brown y } \\
\text { Lauderdale, } 2006 \text { (133). }\end{array}$ \\
\hline $\begin{array}{l}\text { Biopolimeros: polihidroxialcanoatos } \\
\text { (PHA), y los más conocidos entre ellos } \\
\text { son poli (beta-hidroxibutirato; PHB), } \\
\text { poli (beta-hidroxivalerato; PHV) y poli } \\
\text { (hidroxibutirato-co-valerato; PHB -V) }\end{array}$ & $\begin{array}{l}\text { Cupriavidus necato: acumula } \\
\text { aproximadamente el } 80 \% \text { de su masa } \\
\text { seca en el polímero y utiliza diferentes } \\
\text { tipos de sustratos, como glucosa, } \\
\text { fructosa y glicerina en bruto }\end{array}$ & $\begin{array}{c}\text { Philip et al., } 2007 \text { (134); Figueiredo et } \\
\text { al., } 2014 \text { (135); Mohanty et al., } 2000 \\
\text { (136). }\end{array}$ \\
\hline
\end{tabular}




\begin{tabular}{|c|c|c|}
\hline Microorganismo & Utilidad & Biliografia \\
\hline $\begin{array}{c}\text { Aumento de la biomasa de las } \\
\text { plantas o aumentar los rendimientos } \\
\text { de productos de interés agrícola o } \\
\text { farmacológico }\end{array}$ & $\begin{array}{c}\text { Mejora de la nutrición de las plantas, } \\
\text { la protección de patógenos, la } \\
\text { tolerancia al estrés y el suministro de la } \\
\text { estructura del suelo }\end{array}$ & $\begin{array}{c}\text { Boyer et al., 2016 (137); Gabriele } \\
\text { et al., 2016 (138); Köhl et al., 2016 } \\
\text { (139); Smith y Read, 2008 (140). }\end{array}$ \\
\hline $\begin{array}{c}\text { Biofertilizantes: hongos micorrízicos } \\
\text { arbusculares (FAM) }\end{array}$ & $\begin{array}{c}\text { Producción con bajo consumo de } \\
\text { productos químicos }\end{array}$ & Lanfranco et al., 2016 (141) \\
\hline Tecnología de micorrizas & $\begin{array}{c}\text { Aumentar la abundancia y diversidad } \\
\text { de las FMA y, en consecuencia, la } \\
\text { eficiencia de la producción de cultivos. }\end{array}$ & Rillig et al., 2016 (142) \\
\hline
\end{tabular}

\section{Microbiología y Tecnológica Médica}

La participación de microorganismos en la generación de productos o servicios médicos implica cuatro aspectos distintos: (1) control biológico de enfermedades, (2) producción de vacunas, (3) producción de antibióticos y (4) producción de productos bioterapéuticos (hormonas, biomateriales, y otros).

Tabla 7. Microorganismos y tecnología médica. Se presentan los microorganismos, la utilidad asociada a los procesos de tecnología ambiental y la bibliografía donde se reporta.

\begin{tabular}{|c|c|c|}
\hline Microorganismos & Utilidad & Bibliografia \\
\hline $\begin{array}{l}\text { Introducción de la bacteria Wolbachia } \\
\text { como un endosimbionte del mosquito } \\
\text { Aedes aegypti }\end{array}$ & $\begin{array}{l}\text { Controlar la propagación de vectores } \\
\text { parásitos como los de los géneros } \\
\text { Aedes y Anopheles, reduce la vida útil } \\
\text { del mosquito }\end{array}$ & $\begin{array}{l}\text { Walker et al., 2011(143); Cook et al., } \\
2008 \text { (144) ; Turley et al., } 2009 \text { (145); } \\
\text { Bian et al., 2010(146) }\end{array}$ \\
\hline $\begin{array}{l}\text { Mosquitos que contienen la cepa } \\
\text { Wolbachia wMelPop-CLA }\end{array}$ & $\begin{array}{l}\text { Reducción de aproximadamente } \\
\text { el } 50 \% \text { de la supervivencia de las } \\
\text { hembras en comparación con los } \\
\text { mosquitos sin la cepa. }\end{array}$ & McMeniman et al., 2009 (147) \\
\hline $\begin{array}{l}\text { Activación de las endotoxinas (Cry } \\
\text { y Cyt) producida naturalmente por } \\
\text { la bacteria B. thuringiensis serotipo } \\
\text { israelensis (Bti) }\end{array}$ & $\begin{array}{l}\text { Prevenir la proliferación del vector } \\
\text { del virus del dengue. Estas toxinas, } \\
\text { son cristales inactivos que cuando son } \\
\text { ingeridos por las larvas de Aedes, son } \\
\text { solubilizados por proteasas intestinales } \\
\text { lisis celular, septicemia y muerte. }\end{array}$ & $\begin{array}{l}\text { Gill et al., } 1992(148) \text {; Mohiddin } \\
\text { et al., } 2016(149) \text {; Setha et al., } \\
2016 \text { (150); Paris et al., } 2011 \text {, } 2012 \\
(152,153) \text {; Wu et al., } 2016(154) ; \\
\text { Durbin, } 2016 \text { (155) ; Pitisuttithum y } \\
\text { Bouckenooghe, } 2016(156) .\end{array}$ \\
\hline
\end{tabular}




\section{Vacunas}

Técnicas biotecnológicas utilizadas en la producción de los tipos de vacunas actualmente disponibles (1), Tabla 8.

Tabla 8. Tipos de vacunas y descripción.

\begin{tabular}{|c|c|c|}
\hline Tipos de vacunas & \multicolumn{2}{|c|}{ Descripción } \\
\hline Vacunas atenuadas o vivas & \multicolumn{2}{|c|}{ Utilizan patógenos atenuados } \\
\hline \multirow{6}{*}{ Vacunas inactivadas } & \multicolumn{2}{|c|}{$\begin{array}{l}\text { Contienen patógenos completamente inactivados o fraccionados o solo } \\
\text { componentes antigénicos de estos patógenos, subdivididos: }\end{array}$} \\
\hline & B1 & Enteros o fraccionados \\
\hline & B2 vacunas de subunidades & $\begin{array}{l}\text { Utilizan proteínas, péptidos o ácidos } \\
\text { nucleicos como antígenos }\end{array}$ \\
\hline & B3 toxoides & $\begin{array}{l}\text { Usan toxinas patógenas inactivadas como } \\
\text { antígenos }\end{array}$ \\
\hline & B4 vacunas de carbohidratos & $\begin{array}{l}\text { Producidas a partir de polisacáridos, } \\
\text { oligosacáridos y glicanos }\end{array}$ \\
\hline & B5 vacunas conjugadas & $\begin{array}{l}\text { Tienen polisacáridos combinados con } \\
\text { proteínas de transporte }\end{array}$ \\
\hline Vacunas de ADN & \multicolumn{2}{|c|}{$\begin{array}{l}\text { Contienen plásmidos que contienen genes que codifican antígenos } \\
\text { inmunogénicos }\end{array}$} \\
\hline Vacunas recombinantes & \multicolumn{2}{|c|}{$\begin{array}{c}\text { Contienen virus diseñados para transportar genes que codifican antígenos de } \\
\text { otros virus que causan enfermedades. }\end{array}$} \\
\hline
\end{tabular}

Tabla 9. Caracteristicas de las vacunas inactivadas; vacunas de subunidades, toxoides y carbohidratos.

\begin{tabular}{|l|l|}
\hline \multicolumn{2}{|l|}{ Vacunas inactivadas } \\
\hline Vacunas de subunidades & Referencias \\
\hline Características & Nabel, 2013 (157) \\
\hline Estimuladores efectivos de las respuestas inmunes humorales & Nabel, 2013 (157) \\
\hline $\begin{array}{l}\text { Requieren dosis múltiples para la inmunidad a largo plazo, ya que no estimulan la } \\
\text { producción de inmunoglobulina A (IgA) o respuestas de células T citotóxicas porque el } \\
\text { virus no lo hace }\end{array}$ & $\begin{array}{l}\text { Bobbala y Hook, 2016 (158); } \\
\text { Reed y Schmidt et al., 2016 } \\
\text { (159); Gillison et al., 2008 } \\
\text { (160); Roden y Wu, 2006 } \\
\text { (161). }\end{array}$ \\
\hline $\begin{array}{l}\text { Actualmente disponibles para la hepatitis A, la rabia, el cólera, la influenza, la } \\
\text { poliomielitis (Salk), la fiebre tifoidea y la tos ferina, Streptococcus pneumoniae, virus de } \\
\text { la hepatitis B, y VPH (tipos 16 y 18 representan aproximadamente el 70\% de los casos). }\end{array}$
\end{tabular}




\section{Carácterísticas}

Son poco reactogénicas, lo que es una ventaja en términos de efectos adversos y desventaja en términos de estimular respuestas inmunes potentes y duraderas

Requieren la administración conjunta de adyuvantes eficientes para activar y modular las respuestas inmunitarias

Son más seguras porque la virulencia de los organismos muertos no se puede revertir

\section{Bibliografía}

Bobbala y Hook, 2016 (158)

Reed y Schmidt et al., 2016

(159)

Nabel, 2013 (157)

\section{Vacunas de toxoides}

\section{Carácterísticas}

Estimulan la respuesta inmune mediante el uso de toxinas patógenas inactivadas como antígenos

Disponibles para el tétanos, la difteria y el ántrax

\section{Bibliografía}

Nabel, 2013 (157)

Nabel, 2013 (157)

\section{Las vacunas de carbohidratos}

\section{Carácterísticas}

Las respuestas de defensa del huésped es estimulada por los los receptores de reconocimiento de glicocálix (PRR)

La baja inmunogenicidad es un obstáculo importante para la fabricación de vacunas de carbohidratos, y debido a la falta de protección inmunológica a largo plazo. Pocas de estas vacunas están disponibles comercialmente en la actualidad: vacunas contra Salmonella typhi y Neisseria meningitides

Los enlaces covalentes tradicionales entre los carbohidratos y las proteínas portadoras se han utilizado para aumentar las respuestas inmunes a los antígenos polisacáridos, obteniendo así vacunas conjugadas

Las vacunas de proteína-polisacárido inducen memoria inmunológica, una protección que dura más que la inducida por el uso de antígenos polisacáridos simples. Las vacunas conjugadas ya se utilizan actualmente en el control de Haemophilus influenza tipo B y S. pneumoniae

\section{Bibliografía}

Astronomo y Burton, 2010

(162); Pifferi et al., 2017)

(163).

Keitel et al., 1994(164); King et al., 1996 (165)

Nishat y Andreana, 2016

(166).

Knuf et al., 2011 (167) ;

Frenck y Yeh, 2012 (168);

Pichichero, 2013 (169).

Tabla 10. Caracteristicas de las vacunas de ADN.

\section{Las vacunas de ADN}

\section{Bibliografía}

Consisten en un plásmido de expresión que contiene genes que codifican uno o más antígenos inmunogénicos de interés

El uso de promotores virales mejora la expresión génica y mejora la estabilidad del ARNm relacionada con la síntesis de antígenos

Actualmente se estudias nuevos adyuvantes inmunológicos y métodos de inserción de este material en las células del organismo huésped. La investigación microbiológica se han centrado en el VIH, la hepatitis B, la hepatitis C, la influenza y el VPH.
Robinson, 1997 (170)

Robinson, 1997 (170)

Brouillette et al., 2016 (171) 


\begin{tabular}{|l|l|}
\hline Carácterísticas & Bibliografía \\
\hline Inserción con aplicaciones potenciales en humanos :biobolística (en estudio) & $\begin{array}{l}\text { Fynan et al., 1993 (172); } \\
\text { Brouillette et al., 2016 (171) }\end{array}$ \\
\hline Administración intradérmica sin agujas del plásmido de ADN (estudios en primates). & Rao et al., 2006(173) \\
\hline $\begin{array}{l}\text { Tatuaje intradérmico:en el cual el plásmido de ADN se envía a la capa epidérmica } \\
\text { utilizando miles de inyecciones (en estudio). }\end{array}$ & Becker et al., 2008 (174) \\
\hline
\end{tabular}

Tabla 11. Características de las vacunas recombinantes.

\section{Las vacunas recombinantes (genéticas)}

\section{Carácterísticas}

\section{Bibliografía}

Se preparan a partir de virus diseñados para transportar genes que codifican antígenos de otros virus que causan enfermedades para su expresión en el huésped después de la inoculación

La inmunidad se atribuye a la capacidad del virus recombinante para expresar el gen de interés en niveles altos dentro de las células huésped

Los vectores virales utilizados para este propósito se atenúan, son intrínsecamente seguros.

Los virus con mayor potencial para la producción de este tipo de vacuna son aquellos con un genoma extenso

He et al., 2000 (175)

He et al., 2000 (175)

He et al., 2000 (175)

He et al., 2000 (175)

Tabla 12. Características de los anticuerpos monoclonales.

\section{Anticuerpos monoclonales (mAbs).}

\section{Carácterísticas}

Emplea microorganismos, como fagos, levaduras, bacterias y virus, para mostrar repertorios de fragmentos de anticuerpos de dominio variable (ScFvs) de una sola cadena, fragmentos de unión a antígenos (Fab) o anticuerpos de dominio (Dabs) en sus superficies

Pueden obtenerse directamente de las células de memoria B de pacientes infectados con virus o de células de linfocitos de ratón

Se han utilizado para el tratamiento de enfermedades infecciosas.

Palivizumab, un anticuerpo monoclonal neutralizador del virus respiratorio humano sincitial (RSV) que bloquea la replicación del virus

Raxibacumab, que evita la unión del antígeno protector de la toxina del ántrax a sus receptores en las células huésped

Representan una de las mayores clases de fármacos en desarrollo, y entre 2010 y 2014, 17 de los 54 fármacos proteicos aprobados fueron mAb (31.5\%)

\section{Bibliografía}

Carter, 2006 (176)

Marasco y Sui, 2007 (178)

The IMpact-RSV Study

Group, 1998 (179)

Kummerfeldt, 2014 (180)

Baldo, 2016 (181)

Baldo, 2016 (181) 


\section{Microorganismos y productos de interés farmaceútico}

El uso de células microbianas recombinantes ha permitido la producción a gran escala de un gran número de productos de interés farmacéutico, como hormonas, anticoagulantes, proteínas de alto valor, anticuerpos o antígenos y otros. Esto ha sido crucial para determinar la relación estructura-función de las proteínas, así como para desarrollar una mejor comprensión de las reacciones del sistema inmune, la biología celular y los eventos de señalización (Bajaj et al. , 2012 (182); Avendaño et al., 2016 (183) ; Borghese et al., 2016(184).

La necesidad de nuevos biomateriales funcionales en fármacos emergentes ha potenciado los estudios de ingeniería metabólica de moléculas a partir de microorganismos (Vázquez y Villaverde, 2013(185);Rodríguez-Carmona y Villaverde, 2010) (186).

Más de dos millones de personas en los Estados Unidos se ven afectadas anualmente por bacterias resistentes a los antibióticos (Nizet, 2015)(187). Segín el Centro para el Control y la Prevención de Enfermedades Estados Unidos el Staphylococcus aureus resistente a la meticilina (MRSA) representa aproximadamente 10,000 casos de infecciones en el torrente sanguíneo adquiridas en el hospital, mientras que Clostridium difficile, asociado con diarrea, es la infección más común en los Estados Unidos, con más de 80,000 casos anuales estimados (188), lo que genera inversión importante para la identificación de nuevos y mejores fármacos con exploración de biofactorías con microorganismos como E. coli y S. cerevisiae (189).

Las técnicas de ingeniería de proteínas, especialmente la mutagénesis dirigida (SDM), que permite la sustitución, eliminación o inserción de uno o más aminoácidos en la secuencia de una proteína, permite la disponibilidad de biobetadores menos costosos, que son la principal clase creciente de productos biofarmacéuticos (190-191).

Tabla 13. Producto biofarmaceutico, utilidad y bibliografía asociada.

\begin{tabular}{|c|c|c|}
\hline Producto & Utilidad & Bibliografía \\
\hline Teixobactina & $\begin{array}{c}\text { Capaz de eliminar el SARM } \\
\text { (Staphylococcus aureus resistente a } \\
\text { la meticilina), se dirige a los lípidos } \\
\text { esenciales para el mantenimiento de la } \\
\text { pared celular bacteriana }\end{array}$ & Borghesi y Stronati, 2015 (192). \\
\hline Insulina humana & $\begin{array}{c}\text { Obtenida por expresión heteróloga a } \\
\text { través de E. coli , para el tratamiento } \\
\text { de la diabetes tipo I y tipo II ( FDA, } \\
1982 \text { ) }\end{array}$ & ;Sánchez-García et al., 2016(190) \\
\hline
\end{tabular}




\begin{tabular}{|c|c|c|}
\hline Producto & Utilidad & Bibliografía \\
\hline $\begin{array}{l}\text { Hormonas (calcitonina, hormona } \\
\text { paratiroidea, hormona del crecimiento } \\
\text { humano, glucagón y somatropina), } \\
\text { interferones e interleucina por } \\
\text { proteínas heterólogas de E. coli. }\end{array}$ & $\begin{array}{l}\text { El 30\% de las proteínas recombinantes } \\
\text { disponibles en el mercado se producen } \\
\text { actualmente en sistemas procarióticos }\end{array}$ & $\begin{array}{l}\text { Ferrer-Miralles et al., 2009(191); } \\
\text { Overton, 2014(192) }\end{array}$ \\
\hline $\begin{array}{l}\text { 4-hidroxibenzoato, la tirosina y la } \\
\text { fenilalanina }\end{array}$ & $\begin{array}{c}\text { 1,777 productos no nativos de E. coli } \\
\text {, de los cuales } 279 \text { tienen aplicaciones } \\
\text { comerciales }\end{array}$ & Zhang et al., 2016(193) \\
\hline $\begin{array}{c}\text { Insulina, análogos de insulina } \\
\text { y glucagón, hormonas, vacunas } \\
\text { (antígeno de superficie del virus de } \\
\text { la hepatitis B) y partículas similares a } \\
\text { virus (VLP) }\end{array}$ & Obtenidas de S. cerevisiae & Ferrer-Miralles et al., 2009(191). \\
\hline $\begin{array}{c}\text { Síntesis biológica controlada de } \\
\text { calcitonina, aminoácidos (glutamato y } \\
\text { lisina), proinsulina }\end{array}$ & $\begin{array}{l}\text { A partir de cepas modificadas de } S \text {. } \\
\text { carnosus, Corynebacterium glutamicum, } \\
\text { B. subtilis y Lactococcus lactis }\end{array}$ & $\begin{array}{l}\text { Olmos-Soto y Contreras-Flores. } 2003 \\
\text { (194) ; Sandgathe et al., } 2003 \text { (195); } \\
\text { Liu et al., } 2016 \text { (196);Cano-Garrido et } \\
\text { al., 2016(197) }\end{array}$ \\
\hline $\begin{array}{l}\text { Los polisacáridos de metabolitos } \\
\text { secundarios }\end{array}$ & $\begin{array}{l}\text { Utilizando Ganoderma lucidum, } \\
\text { Cordyceps sinensis y C. militaris }\end{array}$ & $\begin{array}{l}\text { Paterson, } 2006 \text { (198) , } 2008 \text { (199) ; } \\
\text { Wadt et al., } 2015 \text { (200) }\end{array}$ \\
\hline $\begin{array}{l}\text { Síntesis de Taxol } \\
\text { (antineoplásico) }\end{array}$ & $\begin{array}{c}\text { A partir de hongos endófitos } \\
\text { como Metarhizium anisopliae y } C . \\
\text { gloeosporioides }\end{array}$ & $\begin{array}{l}\text { Gangadevi y Muthumary, } 2008 \text { (201) ; } \\
\text { Liu et al., } 2009 \text { (196) }\end{array}$ \\
\hline
\end{tabular}

\section{Microbiología y Tecnológica de Materiales}

La aplicación de técnicas biotecnológicas a la microbiología también ha permitido obtener una gran diversidad de biomateriales y biosensores. Los biomateriales son productos artificiales o naturales, generalmente sintetizados por microorganismos en diferentes condiciones ambientales, que pueden actuar en sistemas biológicos (tejidos u órganos) (1).
Una familia importante de biomateriales incluye los bioplásticos. Los bioplásticos son poliésteres que se acumulan intracelularmente en microorganismos en forma de gránulos de almacenamiento, con propiedades fisicoquímicas similares a los plásticos petroquímicos, biodegradables y biocompatibles (202).

El bioplástico también puede producirse como un subproducto de la biorrefinería utilizando fermentación acidogénica o pirólisis 
de biomasa lignocelulósica, así como un subproducto del tratamiento biológico de desechos sólidos o líquidos (203).

\section{Los bioplásticos se utilizan en la fabricación} de materiales médicos de alto valor agregado: mejores propiedades biomecánicas y bioactividad, como películas que funcionan como vehículos para la administración de fármacos (204).

Tabla 14. Biomaterial, microorganismos, utilidad y referencias asociadas.

\begin{tabular}{|c|c|c|}
\hline Biomateriales/ microorganismo & Utilidad & Referencias \\
\hline $\begin{array}{c}\text { Esporas de promotores del crecimiento } \\
\text { como } T \text {. harzianum }\end{array}$ & Control de plagas agrícolas en el futuro & Accinelli et al., 2016(205) \\
\hline $\begin{array}{l}\text { Los polisacáridos de origen } \\
\text { microbiano: chitosán, el alginato, la } \\
\text { goma xantana y la celulosa. }\end{array}$ & $\begin{array}{l}\text { Uso médico debido a sus propiedades, } \\
\text { entre ellas, que son renovables, } \\
\text { biodegradables e imitan los } \\
\text { componentes de la extracelular. matriz, } \\
\text { que los hace elementos clave en los } \\
\text { procesos biológicos }\end{array}$ & $\begin{array}{l}\text { Pires y Moraes, } 2015 \text { (206); Ruholahi } \\
\text { et al., 2016(210) ;Abdel-Gawad et al., } \\
\qquad 2017 \text { (211) }\end{array}$ \\
\hline $\begin{array}{l}\text { Promotores del crecimiento como } T \text {. } \\
\text { harzianum }\end{array}$ & $\begin{array}{l}\text { Recubrimiento de semillas de especies } \\
\text { agronómicas para control de plagas } \\
\text { agrícolas }\end{array}$ & Accinelli et al., 2016 (205) \\
\hline Bioplásticos & $\begin{array}{l}\text { Aumento, dentro de la construcción } \\
\text { civil, de materiales que tienen poca } \\
\text { energía incorporada, lo que contribuye } \\
\text { a la eficiencia energética }\end{array}$ & Ivanov y Stabnikov, 2016 (203) \\
\hline Quitosano & $\begin{array}{c}\text { Reparación de piel, los huesos y el } \\
\text { cartílago }\end{array}$ & Khor y Lim, 2003 (204) \\
\hline Quitosano & $\begin{array}{l}\text { Quelación de metales pesados e } \\
\text { inhibición de agentes microbianos } \\
\text { patógenos en el agua contaminada }\end{array}$ & $\begin{array}{c}\text { Ruholahi et al., } 2016(210) \text {; Tayel et } \\
\text { al., 2016a (212) }\end{array}$ \\
\hline $\begin{array}{l}\text { Alginato polisacárido sintetizado por } \\
\text { algas pardas y dos géneros de bacterias: } \\
\text { Pseudomonas y Azotobacter }\end{array}$ & $\begin{array}{l}\text { Encapsulación o liberación controlada } \\
\text { de fármacos, enzimas o células, o como } \\
\text { una matriz para la ingeniería de tejidos }\end{array}$ & $\begin{array}{l}\text { Hay et al., } 2013 \text { (213) ; Maleki et al., } \\
2016 \text { (214); Andersen et al., } 2012 \text { (58) } \\
\text {; Lee y Mooney, } 2012(215)\end{array}$ \\
\hline $\begin{array}{l}\text { Alginato y el quitosano se combinan } \\
\text { en un complejo de polielectrolito } \\
\text { (PEC) }\end{array}$ & $\begin{array}{l}\text { Membranas delgadas y transparentes: } \\
\text { buena absorción de fluidos fisiológicos, } \\
\text { así como la incorporación de varios } \\
\text { compuestos bioactivos }\end{array}$ & Pires y Moraes, 2015 (206) \\
\hline
\end{tabular}




\begin{tabular}{|c|c|c|}
\hline Biomateriales/ microorganismo & Utilidad & Referencias \\
\hline $\begin{array}{c}\text { Goma xantana combinada con } \\
\text { quitosano }\end{array}$ & $\begin{array}{c}\text { Inmovilización de enzimas y } \\
\text { producción de micropartículas y } \\
\text { membranas }\end{array}$ & $\begin{array}{c}\text { Bejenariu et al., 2008 (207); Barua et } \\
\text { al., 2016 (208); Velu et al., 2016(209) }\end{array}$ \\
\hline $\begin{array}{c}\text { Celulosa sintetizada (en abundancia) } \\
\text { por bacterias como Gluconacetobacter } \\
\text { xylinus }\end{array}$ & $\begin{array}{c}\text { Diálisis y andamios para la ingeniería } \\
\text { de tejidos, tratamiento de lesiones } \\
\text { cutáneas y el reemplazo de vasos } \\
\text { sanguíneos de pequeño diámetro. }\end{array}$ & $\begin{array}{c}\text { Pires et al., 2015 (206); Czaja et al., } \\
\text { 2006 (212) }\end{array}$ \\
\hline
\end{tabular}

\section{Biosensores}

Los microorganismos como una alternativa en la producción de biosensores se debe principalmente a la capacidad de producirlos masivamente a través del cultivo celular (216).Los biosensores integran microorganismos con un transductor físico para generar una señal medible proporcional a la concentración de analitos, lo que permite una detección rápida y precisa de los objetivos de análisis en diversos campos, como medicina, monitoreo ambiental, procesamiento de alimentos y otros (216-219).

La técnica de ADN recombinante ha facilitado la disponibilidad de biosensores micro- bianos, esta técnica consiste en la construcción de cepas microbianas recombinantes que contienen un gen informador (lux, GFP o lac Z), es decir, un gen que genera una señal cuando ocurre la reacción biológica entre un microorganismo y un analito (219-220).

A pesar del gran avance realizado por la biotecnología, los microorganismos nuevos aún deben evaluarse para determinar su eficacia, aún deben desarrollarse métodos más precisos para inmovilizar células microbianas y las técnicas de inducción deben evaluarse continuamente porque pueden variar en términos de su eficiencia según el analito.

Tabla 15. Biosensor, aplicación y referencias asociadas.

\begin{tabular}{|c|c|c|}
\hline Biosensor & Aplicación & Bibliografia \\
\hline $\begin{array}{c}\text { E. coli recombinante inmovilizada que } \\
\text { expresan organofosforado hidrolasa } \\
(\text { OPH }) .\end{array}$ & Monitoreo de contaminantes & $\begin{array}{c}\text { Mulchandani et al., 1998 (221); Kim } \\
\text { HJ et al., 2016(222) }\end{array}$ \\
\hline $\begin{array}{c}\text { Celulas E. coli como biosensores } \\
\text { CadC-T7 }\end{array}$ & $\begin{array}{c}\text { alta especificidad para la detección de } \\
\text { metales pesados }\end{array}$ & Kim KR et al., 2016(223) \\
\hline $\begin{array}{c}\text { Biosensor en el que las células expresan } \\
\beta \text {-galactosidasa en presencia de cadmio }\end{array}$ & Monitoreo ambiental del cadmio & Shin, 2016 (224) \\
\hline
\end{tabular}




\begin{tabular}{|c|c|c|}
\hline Biosensor & Aplicación & Bibliografia \\
\hline E. coli bioluminiscente & $\begin{array}{l}\text { Señalar el daño en el ADN, la } \\
\text { producción de radicales superóxido y } \\
\text { el daño a la membrana causado por } \\
\text { líquidos potencialmente tóxicos }\end{array}$ & Bharadwaj et al., 2017 (225) \\
\hline Biosensor de P. putida & $\begin{array}{l}\text { Biosensor para catecol, nitrofenol, } \\
\text { benceno, tolueno y otros }\end{array}$ & $\begin{array}{c}\text { Rasinger et al., } 2005 \text { (226) ; Timur } \\
\text { et al., } 2007 \text { (227) ; Banik et al., } 2008 \\
(228)\end{array}$ \\
\hline Biosensor de S. cerevisiae & Biosensor para $\mathrm{Cu} 2++$ & Stoycheva et al., 2007 (229) \\
\hline $\begin{array}{l}\text { Biosensor de Acidithiobacillus } \\
\text { ferrooxidans y Leptospirillum } \\
\text { ferrooxidans }\end{array}$ & $\begin{array}{c}\text { Biosensor para Fe 2+, S } 2 \text { O } 32-\text {, } \\
\text { Cr } 2 \text { O } 72-\text {, y otros }\end{array}$ & $\begin{array}{c}\text { Zlatev et al., } 2006(230) \text {; Stoytcheva } \\
\text { et al., } 2009(229)\end{array}$ \\
\hline Biosensor de Gluconobacter oxydans & Biosensor para propanodiol y etanol & $\begin{array}{c}\text { Katrlik et al., } 2007 \text { (231); Valach et } \\
\text { al., } 2009 \text { (232) }\end{array}$ \\
\hline
\end{tabular}

\section{Otras Consideraciones}

\section{Declaracion de conflicto de interes}

Los autores declaran que la investigación se llevó a cabo en ausencia de cualquier relación comercial o financiera que pudiera interpretarse como un posible conflicto de intereses.

\section{Referencias}

1. Vitorino L.C., Bessa A.L.(2017). Technological Microbiology: Development and Applications. Front Microbiol. 2017; 8: 827. Published online 2017 May 10. doi: $10.3389 /$ fmicb. 2017.00827

2. McGovern P. E., Glusker D. L., Exner L. J. (1996). Neolithic resinated wine. Nature 381 480-481. 10.1038/381480a0 [Cross Ref]

3. Valamoti SM, Mangafa M., Koukouli-Chrysanthaki CH, Malamidou D. (2007). Prensados de uva del norte de Grecia: ¿el vino más antiguo del Egeo? La antigüedad 81 54-61. 10.1017 / S0003598X00094837
4. Borneman AR, Schmidt SA, Pretorius IS (2013). A la vanguardia de la biotecnología de la uva y el vino. Tendencias genet. 29 263-271. 10.1016/j. tig.2012.10.014 [ PubMed ]

5. Samuel D. (1996). Investigation of ancient Egyptian baking and brewing methods by correlative microscopy. Science 273 488-490. 10.1126/science.273.5274.488 [PubMed] [Cross Ref]

6. Sicard D., Legras J.-L. (2011). Bread, beer and wine: yeast domestication in the Saccharomyces sensu stricto complex. C. R. Biol. 334 229-236. 10.1016/j. crvi.2010.12.016 [PubMed] [Cross Ref]

7. Gal J. (2008). El descubrimiento de la enantioselectividad biológica: Louis Pasteur y la fermentación del ácido tartárico, revisión y análisis de 1857-A 150 años después. La quiralidad 20 5-19. 10.1002 / chir.20494 [ PubMed ]

8. Pasteur L. (2002). Summary report of the experiments conducted at Pouilly-le-Fort, near Melun, on the anthrax vaccination, 1881. Yale J. Biol. Med. 75 59-62. [PMC free article] [PubMed]

9. Plotkin SA, Orenstein WA, Offit PA (2008). Vacunas 
de $5^{a}$ ed. Filadelfia, PA: Saunders / Elsevier; 399-434.

10. Wang Z., Zhuge J., Fang H., Prior BA (2001). Producción de glicerol por fermentación microbiana: una revisión. Biotecnol. Adv. 19 201-223. 10.1016 / S0734-9750 (01) 00060-X [ PubMed ]

11. Neushul P. (1993). La ciencia, el gobierno y la producción en masa de la penicilina. J. Hist. Medicina. Allied Sci. 48 371-395. 10.1093 / jhmas / 48.4 .371 [ PubMed ]

12. Jacob F., Perrin D., Sanchez C., Monod J. (1960). Loperón: grupo de géneros de expresión coordina para un operador. Comp. Desgarrar. Acad Sci. París 250 1727-1729. [ PubMed ]

13. Ames BN, Martin RG (1964). Aspectos bioquímicos de la genética: el operón. Ana. Rev. Biochem. 33 235-258. 10.1146/ annurev.bi.33.070164.001315 [ PubMed ]

14. Holloway BW (1969). Genética de las pseudomonas . Bacteriol. Rev. 33 419-443. [ Artículo libre de PMC ] [ PubMed ]

15. Holloway BW (2014). "Mis recuerdos de las pseudomonas en el siglo veinte", en Pseudomonas eds Ramos J.-L., Goldberg JB, Filloux A., editores. (Dordrecht: Springer;) 289-314. 10.1007 / 978-94-017-9555-511

16. Smith HO, Nathans D. (1973). Una nomenclatura sugerida para la modificación del huésped bacteriano y los sistemas de restricción y sus enzimas. J. Mol. Biol. 81 419-423. 10.1016 / 0022-2836 (73) 901526 [ PubMed ]

17. Arber W. (1974). Modificación y restricción del ADN. Prog. Nucleic Acid Res. Mol. Biol. 14 1-37. 10.1016 / S0079-6603 (08) 60204-4 [ PubMed ]

18. Walsh G. (2012). Nuevos biofarmacéuticos. Biofarm. En t. 25 34-38.

19. Cohen SN, Chang AC, Boyer HW, Helling RB (1973). Construcción de plásmidos bacterianos biológicamente funcionales in vitro . Proc. Natl Acad Sci. USA 70 3240-3244. 10.1073 / pnas.70.11.3240 [ Artículo libre de PMC ] [ PubMed ]
20. Berg P., Mertz JE (2010). Reflexiones personales sobre los orígenes y el surgimiento de la tecnología del ADN recombinante. Genética 184 9-17. 10.1534 / genetics.109.112144 [ Artículo libre de PMC ] [ PubMed ]

21. Cheng L., Chen W., Adams TS, Wei X., Li L., McCormack ML, y otros. (2016). Los hongos micorrícicos y las raíces son complementarios en el forrajeo en parches de nutrientes. Ecología 97 2815-2823. 10.1002 / ecy.1514 [ PubMed ]

22. Saiki R. K., Gelfand D. H., Stoffel S., Scharf S. J., Higuchi R., Horn G. T., et al. (1988). Primer-directed enzymatic amplification of DNA with a thermostable DNA polymerase. Science 239 487-491. 10.1126/ science.2448875 [PubMed] [Cross Ref]

23. Simon D., Chopin A. (1988). Construcción de una familia de plásmidos vectoriales y su uso para la clonación molecular en Streptococcus lactis. Biochimie 70 559-566. 10.1016/0300-9084 (88) 90093-4 [ PubMed ]

24. Olsen J. L. (2016). "Polymerase chain reaction," in Encyclopedia of Immunotoxicology ed. Vohr H.-W., editor. (Berlin: Springer; ) 715-720. 10.1007/978-3642-54596-2-1193 [Cross Ref]

25. Woese CR, Fox GE (1977). Estructura filogenética del dominio procariótico: los reinos primarios. Proc. Natl Acad. Sci. USA 74 5088-5090. 10.1073 / pnas.74.11.5088 [ Artículo libre de PMC ] [ PubMed ]

26. Woese CR, Kandler O., Wheelis ML (1990). Hacia un sistema natural de organismos: propuesta para los dominios Archaea, Bacteria y Eucarya. Proc. Natl Acad. Sci. USA 87 4576-4579. 10.1073 / pnas.87.12.4576 [ Artículo libre de PMC ] [ PubMed ]

27. Brown CT, Hug LA, Thomas BC, Sharon I., Castelle CJ, Singh A., et al. (2015). Biología inusual en un grupo que comprende más del $15 \%$ de las bacterias del dominio. Naturaleza 523 208-211. 10.1038 / nature14486 [ PubMed ]

28. Rinke C., Schwientek P., Sczyrba A., Ivanova NN, 
Anderson IJ, Cheng J.-F., et al. (2013). Información sobre la filogenia y el potencial de codificación de la materia oscura microbiana. Nature 499 431-437. 10.1038 / nature12352 [ PubMed]

29. Castelle CJ, Wrighton KC, Thomas BC, Hug LA, Brown CT, Wilkins MJ, et al. (2015). La expansión genómica del dominio Archaea destaca los roles de los organismos de los nuevos filos en el ciclo del carbono anaeróbico. Curr. Biol. 25 690-701. 10.1016/ j.cub.2015.01.014 [ PubMed ]

30. Spang A., Ettema TJG (2016). Diversidad microbiana: el árbol de la vida viene de la edad. Nat. Microbiol. 11605610.1038 / nmicrobiol.2016.56 [ PubMed ]

31. Coker JA (2016). Extremófilos y biotecnología: usos actuales y perspectivas. F1000 Res. 539610.12688 / f1000research.7432.1 [ Artículo libre de PMC ] [ PubMed ]

32. Waditee-Sirisattha R., Kageyama H., Takabe T. (2016). Recursos de microorganismos halófilos y sus aplicaciones en biotecnología industrial y ambiental. OBJETIVOS Microbiol. 2 42-54. 10.3934 / microbial.2016.1.42

33. Anupama, Ravindra P. (2000). Alimentos de valor añadido: proteína unicelular. Biotecnol. Adv. 18 459-479. 10.1016 / S0734-9750 (00) 00045-8 [ PubMed ]

34. Adedayo MR, Ajiboye EA, Akintunde JK, Odaibo A. (2011). Proteínas unicelulares: como potenciador nutricional. Adv. Apl. Sci. Res. 2 396-409.

35. Ma Y.-M., Liang X.-A., Zhang H.-C., Liu R. (2016). Pentapéptido citotóxico y antibiótico cíclico de un aspergillus tamarii endofítico de Ficus carica. J. Agric. Food Chem. 64 3789-3793. 10.1021 / acs. jafc.6b01051 [ PubMed ]

36. Patelski P., Berlowska J., Dziugan P., Pielech-Przybylska K., Balcerek M., Dziekonska U., et al. (2015). Utilisation of sugar beet bagasse for the biosynthesis of yeast SCP. J. Food Eng. 67 32-37. 10.1016/j.jfoodeng.2015.03.031 [Cross Ref]
37. Linko Y.-Y., Javanainen P., Linko S. (1997). Biotecnología de la panificación. Tendencias Alimentaria Sci. Tecnol. 81 339-344. 10.1016 / S0924-2244 (97) 01066-2

38. Takagi H., Shima J. (2015). "Tolerancia al estrés de la levadura de panadería durante los procesos de panificación", en Stress Biology of Yeasts and Fungi eds Takagi H., Kitagaki H., editores. (Tokio: Springer;) 23-42. 10.1007 / 978-4-431-55248-2-2

39. Degré R., Edwards G., Zhang Z. (2008). Nueva preparación de levadura con vitamina D2, un método para producir lo mismo y su uso. US 2008/0138469 .

40. Lipkie TE, Ferruzzi M., Weaver CM (2016). La bioaccesibilidad de la vitamina $\mathrm{D}$ del pan enriquecido con levadura tratada con rayos UV es menor que el pan enriquecido con vitamina D2 cristalina y leche bovina. FASEB J 30918 .

41. Padilla B., Gil J. V., Manzanares P. (2016). Past and future of non-Saccharomyces yeasts: from spoilage microorganisms to biotechnological tools for improving wine aroma complexity. Front. Microbiol. 7:411 10.3389/fmicb.2016.00411 [PMC free article] [PubMed] [Cross Ref]

42. Sauer M. (2016). Industrial production of acetone and butanol by fermentation-100 years later. FEMS Microbiol. Lett. 363:fnw134 10.1093/femsle/ fnw134 [PMC free article] [PubMed] [Cross Ref]

43. Belda I., Ruiz J., Navascués E., Marquina D., Santos A. (2016). Mejora de la liberación de tiol aromático a través de la selección de levaduras con mayor actividad de $\beta$-liasa. En t. J. Comida. Microbiol. 225 1-8. 10.1016 / j.ijfoodmicro.2016.03.001 [ PubMed]

44. Tofalo R., Perpetuini G., Di Gianvito P., Arfelli G., Schirone M., Corsetti A., et al. (2016). Caracterización de levaduras floculantes especializadas para mejorar la fermentación de los vinos espumosos. J. Appl. Microbiol. 120 1574-1584. 10.1111/ jam.13113 [ PubMed ]

45. Satish K. R., Kanmani P., Yuvaraj N., Paari K. A., Pattukumar V., Arul V. (2013). Traditional In- 
dian fermented foods: a rich source of lactic acid bacteria. Int. J. Food. Sci. Nutr. 64 415-428. 10.3109/09637486.2012.746288 [PubMed] [Cross Ref]

46. Mokoena MP, Mutanda T., Olaniran AO (2016). Perspectivas sobre el potencial probiótico de las bacterias del ácido láctico de los alimentos y bebidas fermentadas tradicionales africanas. Comida Nutr. Res. $60: 2963010.3402$ / fnr.v60.29630 [ Artículo libre de PMC ] [ PubMed ]

47. Prasad J., Gill H., Smart J., Gopal PK (2000). Selección y caracterización de cepas de Lactobacillus y Bifidobacterium para su uso como probióticos. En t. Lechería J. 8 993-1002. 10.1016 / S0958-6946 (99) 00024-2

48. Gawkowski D., Chikindas ML (2016). Bebidas probióticas no lácteas: el siguiente paso en la salud humana. Benef. Microbios 4 127-142. 10.3920/ BM2012.0030 [ PubMed ]

49. Enujiugha VN, Badejo AA (2017). Potenciales probióticos de bebidas a base de cereales. Crit. Rev. Food Sci. Nutr. 57 790-804. 10.1080 / 10408398.2014.930018 [ PubMed]

50. Omemu A. M., Akpan I., Bankole M. O., Teniola O. D. (2005). Hydrolysis of raw tuber starches by amylase of Aspergillus niger AM07 isolated from the soil. Afr. J. Biotechnol. 4 19-25.

51. Djekrif-Dakhmouche S., Gheribi-Aoulmi Z., Meraihi Z., Bennamoun L. (2006). Aplicación de un diseño estadístico a la optimización del medio de cultivo para la producción de $\mathrm{a}$-amilasa por Aspergillus niger ATCC 16404 cultivado en polvo de residuos de naranja. J. Food Eng. 73 190-197. 10.1016 / j.jfoodeng.2005.01.021

52. Adejuwon AO, Oluduro AO, Agboola FK, Olutiola PO, Burkhardt BA, Segal SJ (2015). Expresión de a-amilasa por Aspergillus niger : efecto de la fuente de nitrógeno del medio de crecimiento. Adv. Biosci. Bioeng. 3 12-19.

53. Ploss TN, Reilman E., Monteferrante CG, Denham
EL, Piersma S., Lingner A., et al. (2016). Homogeneidad y heterogeneidad en la producción de amilasa por Bacillus subtilis en diferentes condiciones de crecimiento. Microbios Hecho de la célula. 1557 10.1186 / s12934-016-0455-1 [ Artículo libre de PMC ] [ PubMed ]

54. Salman T., Kamal M., Ahmed M., Siddiqa S. M., Khan R. A., Hassan A. (2016). Medium optimization for the production of amylase by Bacillus subtilis RM16 in Shake-flask fermentation. Pak. J. Pharm. Sci. 29 439-444. [PubMed]

55. Rodrigues R. C., Fernandez-Lafuente R. (2010). Lipase from Rhizomucor miehei as a biocatalyst in fats and oils modification. J. Mol. Catal. B Enzym. 66 15-32. 10.1016/j.molcatb.2010.03.008 [Cross Ref]

56. Messias JM, da Costa BZ, Lima VMG, Giese EC, Dekker RFH, Barbosa AM (2011). Lipasas microbianas: producción, propiedades y aplicaciones biotecnológicas. Ciênc. Exatas Tecnol. 32 213-234. 10.5433 / 1679-0375.2011v32n2p213

57. Sharma R., Chisti Y., Banerjee U. C. (2001). Production, purification, characterization, and applications of lipases. Biotechnol. Adv. 19 627-662. 10.1016/ S0734-9750(01)00086-6 [PubMed] [Cross Ref]

58. Andersen T., Strand BL, Formo K., Alsberg E., Christensen BE (2012). "Los alginatos como biomateriales en ingeniería de tejidos”, en Química de carbohidratos: enfoques químicos y biológicos ed. Rauter AP, editor. (Cambridge: The Royal Society of Chemistry;) 227-258. 10.1039 / 9781849732765-00227

59. Ismail A.-M., Abo-Elmagd H., Housseiny MM (2016). Una pectinasa clarificadora de jugo segura de Trichoderma viride EF-8 utilizando pieles de cebolla egipcia. J. Genet. Ing. Biotecnol. 14 153-159. 10.1016 / j.jgeb.2016.05.001

60. Mateo C., Palomo J. M., Fernandez-Lorente G., Guisan J. M., Fernandez-Lafuente R. (2007). Improvement of enzyme activity, stability and selectivity via immobilization techniques. ıEnzyme Microb. Technol. 40 1451-1463. 10.1016/j.enzmictec.2007.01.018 [Cross Ref] 
61. Sheldon R. A. (2007). Enzyme immobilization: the quest for optimum performance. Adv. Synth. Catal. 349 1289-1307. 10.1002/adsc.200700082 [Cross Ref]

62. Carroll AL, Desai SH, Atsumi S. (2016). Producción microbiana de aromas y compuestos aromáticos. Curr. Opin. Biotecnol. 37 8-15. $10.1016 /$ j.copbio.2015.09.003 [ PubMed]

63. Lesage-Meessen L., Lomascolo A., Bonnin E., Thibault J.-F., Buleon A., Roller M., et al. (2002). Un proceso biotecnológico que involucra hongos filamentosos para producir vainillina cristalina natural a partir de salvado de maíz. Apl. Biochem. Biotecnol. 102 141-153. 10.1385 / ABAB: 102-103: 1-6: 141 [ PubMed ]

64. Saerens S., Swiegers J. H. (2016). Enhancement of Coffee Quality and Flavor by Using Pichia kluyveri Yeast Starter Culture for Coffee Fermentation. US 20160058028 A1.

65. Nielsen DR, Yoon SH, Yuan CJ, Prather KL (2010). Ingeniería metabólica de la biosíntesis de acetoína y meso-2,3-butanodiol en E. coli . Biotecnol. J. 5 274284. 10.1002 / biot.200900279 [ PubMed ]

66. Wilson MJ, Jackson TA (2013). Avances en la comercialización de bionematicidas. BioControl 58 715722. 10.1007 / s10526-013-9511-5

67. McRae CF (1988). Enfoques clásicos e inundativos para el control biológico de malezas en comparación. Planta Prot. Cuarto de galón. 3 124-127.

68. Duke SO, Scheffler BE, Boyette CD, Dayan FE (2015). Biotecnología en control de malezas. Enciclopedia Kirk-Othmer de Tecnología Química. Nueva York, Nueva York: John Wiley \& Sons, Inc. 10.1002 / 0471238961.herbduke.a01.pub2

69. Sarwar M. (2015a). Biopesticides: an effective and environmental friendly insect-pests inhibitor line of action. Int. J. Eng. Adv. Res. Technol. 1 10-15.

70. Khan MA, Paul B., Ahmad W., Paul S., Aggarwal C., Khan Z., y otros. (2016). "Potencial de Bacillus thuringiensis en el manejo de plagas de lepidópteros perniciosas", en Plant, Soil and Microbes eds Hakeem KR, Akhtar MS, editores. (Ciudad de Nueva York, NY: Springer International Publishing;) 277-301. 10.1007 / 978-3-319-29573-2_13

71. Popham HJR, Nusawardani T., Bonning BC (2016). "Introducción al uso de baculovirus como insecticidas biológicos", en Baculovirus e Insect Cell Expression Protocols ed. Murhammer DW, editor. (Nueva York, NY: Springer;) 383-392. 10.1007 / 978-14939-3043-2_19 [ PubMed]

72. Sarwar M. (2015b). Microbial insecticides- an ecofriendly effective line of attack for insect pests management. Int. J. Eng. Adv. Res. Technol. 14-9.

73. Mendoza AR, Kiewnick S., Sikora RA (2008). Actividad in vitro de Bacillus firmus contra el nematodo excavador Radopholus similis, el nematodo nudo de la raíz Meloidogyne incognita y el nematodo del tallo Ditylenchus dipsaci . Biocontrol. Sci. Tecnol. 18 377-389. 10.1080 / 09583150801952143

74. Twomey U., Warrior P., Kerry BR, Perry RN (2000). Efectos del nematicida biológico, DiTera, en la eclosión de Globodera rostochiensis y G. pallida . Nematología 2 355-362. 10.1163/ 156854100509114

75. Davies KG, Rowe J., Manzanilla-López R., Opperman CH (2011). Reevaluación del ciclo de vida de la bacteria nematodo-parasitaria Pasteuria penetrans en nematodos de nudo de raíz. Meloidogyne spp. Nematologica 13 825-835. 10.1163/138855410X552670

76. Druzhinina IS, Seidl-Seiboth V., Herrera-Estrella A., Horwitz BA, Kenerley CM, Monet E., et al. (2011). Trichoderma : la genómica del éxito oportunista. Nat. Rev. Microbiol. 9 749-759. 10.1038 / nrmicro2637 [ PubMed ]

77. Jones EE, Rabeendran N., Stewart A. (2014). Biocontrol de la infección por Sclerotinia sclerotiorum del repollo por C. minitans y Trichoderma spp. Biocontrol. Sci. Tecnol. 24 1363-1382. 10.1080 / 09583157.2014 .940847

78. Jones EE, Bienkowski DA, Stewart A. (2016). La importancia de la tolerancia del rango de potencial 
hídrico como factor limitante en Trichoderma spp. Control biológico de Sclerotinia sclerotiorum . Ana. Apl. Biol. 168 41-51. 10.1111 / aab.12240

79. Saravanakumar K., Yu C., Dou K., Wang M., Li Y., Chen J. (2016). Synergistic effect of Trichoderma-derived antifungal metabolites and cell wall degrading enzymes on enhanced biocontrol of Fusarium oxysporum f. sp. Cucumerinum. Biol. Control. $9437-$ 46. 10.1016/j.biocontrol.2015.12.001 [Cross Ref]

80. Carrero-Carrón I., Trapero-Casas JL, Olivares-García C., Monte E., Hermosa R., Jiménez-Díaz RM (2016). Trichoderma asperellum es eficaz para el control biológico del marchitamiento por Verticillium en olivos causado por el patotipo desfoliante de Verticillium dahliae . Crop Prot. 88 45-52. 10.1016 / j.cropro.2016.05.009

81. Khaledi N., Taheri P. (2016). Mecanismos de biocontrol de Trichoderma harzianum contra la pudrición del carbón de soya causada por Macrophomina phaseolina. J. Plant Prot. Res. 56 21-31. 10.1515/ jppr-2016-0004

82. Sahebani N., Hadavi N. (2008). Biological control of the root-knot nematode Meloidogyne javanica by Trichoderma harzianum. Soil Biol. Biochem. 402016 2020. 10.1016/j.soilbio.2008.03.011 [Cross Ref]

83. Feyisa B., Lencho A., Selvaraj T., Getaneh G. (2016). Evaluación de algunos productos botánicos y Trichoderma harzianum contra nematodos de nudo de la raíz ( madera de Chit de Meloidogyne incognita (Kofoid y White)) en tomate. J. Entomol. Nematol. 8 11-18. 10.5897 / JEN2015.0145

84. Sokhandani Z., Moosavi MR, Basirnia T. (2016). Concentraciones óptimas de Trichoderma longibrachiatum y cadusafos para controlar Meloidogyne javanica en plantas de calabacín. J. Nematol. 48 54-63. [ Artículo libre de PMC ] [ PubMed ]

85. Walder F., Boller T., Wiemken A., Courty P.-E. (2016). Regulación de la absorción de fosfato de las plantas en redes micorrízicas comunes: papel de los transportadores de fosfato fúngico intrarrádicos. Señal de Planta. Behav. 11 : e1131372 10.1080/
15592324.2015.1131372 [ Artículo libre de PMC ] [ PubMed ]

86. Lugtenberg B., Kamilova F. (2009). Rizobacterias promotoras del crecimiento de las plantas. Annu. Rev. Microbiol. 63 541-556. 10.1146 / annurev.micro.62.081307.162918 [ PubMed ]

87. Sauer M., Porro D., Mattanovich D., Branduardi P. (2008). Microbial production of organic acids: expanding the markets. Trends Biotechnol. 26 100-108. 10.1016/j.tibtech.2007.11.006 [PubMed] [Cross Ref]

88. Moon HG, Jang Y.-S., Cho C., Lee J., Binkley R., Lee SY (2016). Cien años de fermentación del butanol clostridial. FEMS Microbiol. Letón. 363 fnw001 10.1093 / femsle / fnw001 [ PubMed ]

89. Holm-Nielsen JB, Al Seadi T., Oleskowicz-Popiel P. (2009). El futuro de la digestión anaerobia y la utilización del biogás. Biorour. Tecnol. 100 5478-5484. 10.1016 / j.biortech.2008.12.046 [ PubMed ]

90. Ennouri H., Miladi B., Díaz SZ, Guelfo LAF, Solera R., Hamdi M., et al. (2016). Efecto del tratamiento térmico previo sobre la producción de biogás y el equilibrio de las comunidades microbianas durante la digestión anaeróbica de lodos activados de residuos urbanos e industriales. Biorour. Tecnol. 214 184191. 10.1016 / j.biortech.2016.04.076 [ PubMed ]

91. Mulat DG, Jacobi HF, Feilberg A., Adamsen APS, Richnow H.-H., Nikolausz M. (2016). Cambio de los regímenes de alimentación para demostrar la producción flexible de biogás: efectos sobre el rendimiento del proceso, la estructura de la comunidad microbiana y las vías de metanogénesis. Apl. Reinar. Microbiol. 82 438-449. 10.1128 / AEM.02320-15 [ Artículo libre de PMC ] [ PubMed ]

92. Suksong W., Kongjan P., Prasertsan P., Imai T., O-Thong S. (2016). Optimización y análisis de la comunidad microbiana para la producción de biogás a partir de residuos de residuos sólidos de la industria de la planta de aceite de palma mediante digestión anaeróbica en estado sólido. Biorour. Tecnol. 214 166-174. 10.1016 / j.biortech.2016.04.077 [ PubMed ] 
93. Schlüter A., Bekel T., Diaz N. N., Dondrup M., Eichenlaub R., Gartemann K.-H., et al. (2008). The metagenome of a biogas-producing microbial community of a production-scale biogas plant fermenter analysed by the 454-pyrosequencing technology. J. Biotechnol. 136 77-90. 10.1016/j.jbiotec.2008.05.008 [PubMed] [Cross Ref]

94. Boada L., Sánchez, J., Wen, Y. Indagación exploratoria in vitro de la capacidad degradadora de la cepa comercial Pleurotus ostreatus sobre dos concentraciones de petróleo crudo. NOVA. 2018; 16 (30): 31-35.

95. Liao JC, Mi L., Pontrelli S., Luo S. (2016). Impulsando el futuro: ingeniería microbiana para la producción de biocombustibles sostenibles. Nat. Rev. Microbiol. 14 288-304. 10.1038 / nrmicro.2016.32 [ PubMed ]

96. Meijnen J.-P., Randazzo P., Foulquié-Moreno MR, Brink JVD, Vandecruys P., Stojiljkovic M., et al. (2016). Análisis poligénico y mejora dirigida del rasgo complejo de alta tolerancia al ácido acético en la levadura Saccharomyces cerevisiae. Biotecnol. Biocombustibles 95 10.1186/s13068-015-0421-x [ Artículo libre de PMC ] [ PubMed ]

97. Campuzano, S., Urquijo, L., Valderrama, J. Evaluación de la actividad celulolítica y quitinolítica de hongos filamentosos aislados de rizósfera de cultivos de papa para control de rhizoctonia solani. NOVA. 2017; 15 (28): $45-55$

98. Kuyper M., Hartog MMP, Toirkens MJ, Almering MJH, Winkler AA, van Dijken JP, et al. (2005). Ingeniería metabólica de una cepa que expresa xilosa-isomerasa para una rápida fermentación anaeróbica de xilosa. FEMS Levadura Res. 5 399-409. 10.1016 / j.femsyr.2004.09.010 [ PubMed ]

99. Losordo Z., McBride J., Van Rooyen J., Wenger K., Willies D., Froehlich A., y otros. (2016). Costo competitivo de la producción de etanol de segunda generación a partir de hemicelulosa en una biorrefinería de caña de azúcar brasileña. Biocombustible Bioprod. Bior. 10 589-602. 10.1002 / bbb.1663

100. McIntosh S., Zhang Z., Palmer J., Wong H.-H.,
Doherty W. O. S., Vancov T. (2016). Pilot-scale cellulosic ethanol production using eucalyptus biomass pre-treated by dilute acid and steam explosion. Biofuel Bioprod. Bior. 10 346-358. 10.1002/bbb.1651 [Cross Ref]

101. Appels L., Baevens J., Degrève J., Dewil R. (2008). Principios y potencial de la digestión anaerobia de lodos activados por residuos. Prog. Combustible de energía. Sci. 34 755-781. 10.1016 / j.pecs.2008.06.002

102. Wirth R., Kovacs E., Maroti G., Bagi Z., Rakhely G., Kovacs KL (2012). Caracterización de una comunidad microbiana productora de biogás mediante secuenciación de ADN de próxima generación de lectura corta. Biotecnol. Biofuels 5 : 41 10.1186/ 17546834-5-41 [ Artículo libre de PMC ] [ PubMed ]

103. Chojnacka A., Szczesny y otros. Datos notables sobre una comunidad microbiana productora de metano que procesa efluentes ácidos de la fermentación de melaza de remolacha azucarera. PLoS ONE 10 : e0128008 10.1371/ journal.pone.0128008 [ Artículo libre de PMC ] [ PubMed ]

104. Chouari R., Le PD, Daegelen P., Ginestet P., Weissenbach J., Sghir A. (2005). Novedosos grupos predominantes de arqueas y bacterias revelados por el análisis molecular de un digestor de lodos anaeróbico. Reinar. Microbiol. 7 1104-1115. 10.1111/ j.14622920.2005.00795.x [ PubMed ]

105. Satpathy P., Steinigeweg S., Cypionka H., Engelen B. (2016). Different substrates and starter inocula govern microbial community structures in biogas reactors. Environ. Technol. 37 1441-1450. 10.1080/09593330.2015.1118559 [PubMed] [Cross Ref]

106. Goswami R., Chattopadhyay P., Shome A., Banerjee SN, Chakraborty AK, Mathew AK, y otros. (2016). Una visión general de los mecanismos físico-químicos de la producción de biogás por las comunidades microbianas: un paso hacia la gestión sostenible de los desechos. 3 Biotech 672 10.1007 / s13205-016-0395-9 [ Artículo libre de PMC ] [ PubMed ] 
107. Adham NZ (2002). Intentos de mejorar la fermentación del ácido cítrico por Aspergillus niger en medio de remolacha y melaza. Biorour. Tecnol. 84 97-100. 10.1016 / S0960-8524 (02) 00007-X [ PubMed ]

108. Ikram-ul H., Ali S., Qadeer MA, Iqbal J. (2004). Producción de ácido cítrico por mutantes seleccionados de Aspergillus niger a partir de melaza de cańa. Biorour. Tecnol. 93 125-130. 10.1016 / j.biortech.2003.10.018 [ PubMed ]

109. Wang L., Cao Z., Hou L., Yin L., Wang D., Gao Q. y otros. (2016). Los roles opuestos de agdA y glaA en la producción de ácido cítrico en Aspergillus niger . Apl. Microbiol. Biotecnol. 100 5791-5803. 10.1007 / s00253-016-7324-z [ PubMed ]

110. Gao C., Ma C., Xu P. (2011). Rutas biotecnológicas basadas en la producción de ácido láctico a partir de biomasa. Biotecnol. Adv. 29 930-939. 10.1016 / j.biotechadv.2011.07.022 [ PubMed ]

111. Hofvendahl K., Hahn-Hägerdal B. (2000). Factores que afectan la producción fermentativa de ácido láctico a partir de recursos renovables. Enzyme Microb. Tecnol. 26 87-107. 10.1016 / S0141-0229 (99) 00155-6 [ PubMed ]

112. Papagianni M. (2004). Fungal morphology and metabolite production in submerged mycelia processes. Biotechnol. Adv. 22 189-259. 10.1016/j.biotechadv.2003.09.005 [PubMed] [Cross Ref]

113. Fu YQ, Yin LF, Zhu HY, Jiang R., Li S., Xu Q. (2014). Efectos de las características de los pellets en la fermentación del ácido L-láctico por R. oryzae: morfología de los pellets, diámetro, densidad y estructura interior. Apl. Biochem. Biotecnol. 174 2019-2030. 10.1007 / s12010-014-1146-1 [ PubMed ]

114. Saitoh S., Ishida N., Onishi T., Tokuhiro K., Nagamori E., Kitamoto K., et al. (2005). Genetically engineered wine yeast produces a high concentration of L-lactic acid of extremely high optical purity. Appl. Environ. Microbiol. 71 2789-2792. 10.1128/ AEM.71.5.2789-2792 [PMC free article] [PubMed] [Cross Ref]
115. Valli M., Sauer M., Branduardi P., Borth N., Porro D., Mattanovich D. (2006). Mejora de la producción de ácido láctico en Saccharomyces cerevisiae por clasificación celular para alto $\mathrm{pH}$ intracelular. Apl. Reinar. Microbiol. 72 85492-85499. 10.1128 / AEM.00683-06 [ Artículo libre de PMC ] [ PubMed ]

116. Biebl H., Menzel K., Zeng A.-P., Deckwer W.-D. (1999). Producción microbiana de 1,3-propanodiol. Apl. Microbiol. Biotecnol. 52 289-297. 10.1007 / s002530051523 [ PubMed]

117. Przystałowska H., Zeyland J., Szymanowska-Powałowska D., Szalata M., Słomski R., Lipiński D. (2015). Producción de 1,3-propanodiol por Escherichia coli recombinante que contiene genes de bacterias patógenas. Microbiol. Res. 171 1-7. $10.1016 /$ j.micres.2014.12.007 [ PubMed]

118. Hasan F., Shah AA, Hameed A. (2006). Aplicaciones industriales de lipasas microbianas. Enzima Microb. Tecnol. 39 235-251. 10.1016 / j.enzmictec.2005.10.016

119. Beffa T., Blanc M., Marilley L., Fischer JL, Lyon P.-F., Aragno M. (1996). "Diversidad microbiana taxonómica y metabólica durante el compostaje", en The Science of Composting eds. Bertoldi M., Sequi P., Lemmes B., Papi T., editores. (Dordrecht: Springer;) 149-161. 10.1007 / 978-94-009-1569-5-16

120. Tiquia SM, Wan HC, Tam NFY (2002). Dinámica de la población microbiana y actividades enzimáticas durante el compostaje. Compost sci. Util. 10 150-161. 10.1080 / 1065657X.2002.10702075

121. Hassen A., Belguith K., Jedidi N., Cherif A., Cherif M., Boudabous A. (2001). Caracterización microbiana durante el compostaje de residuos sólidos municipales. Biorour. Tecnol. 80 217-225. 10.1016/ S0960-8524 (01) 00065-7 [ PubMed ]

122. Jamie A., Alshami AS, Maliabari ZO, Ateih MA, Al Hamouz OCS (2016). Inmovilización y actividad catalítica mejorada de la lipasa en MWCNT modificado para el tratamiento de aguas residuales oleosas. Reinar. Prog. Sostener. Energía 35 1441-1449. 10.1002 / ep. 12375 
123. Durán N., Esposito E. (2000). Aplicaciones potenciales de enzimas oxidativas y compuestos de tipo fenoloxidasa en aguas residuales y tratamiento de suelos: una revisión. Apl. Catal. B Environ. 28 83-99. 10.1016 / S0926-3373 (00) 00168-5

124. Tatsumi K., Wada S., Ichikawa H. (1996). Eliminación de clorofenoles de las aguas residuales mediante peroxidasa de rábano picante inmovilizada. Biotecnol. Bioeng. 51 126-130. 10.1002 / (SICI) 1097-0290 (19960705) 51: 1 <126 :: AID-BIT15> 3.0.CO; 2-O [ PubMed ]

125. Tong Z., Qingxiang Z., Hui H., Qin L., Yi Z., Min Q. (1998). Estudio cinético sobre la eliminación de fenol tóxico y clorofenol de las aguas residuales mediante peroxidos de rábano. Quemosfera 37 15711577. 10.1016 / S0045-6535 (98) 00140-4

126. Akay G., Erhan E., Keskinler B., Algur OF (2002). Eliminación de fenol de las aguas residuales utilizando enzimas inmovilizadas por membrana Parte II. Filtración de flujo cruzado. J. Membr. Sci. 206 61-68. 10.1016 / S0376-7388 (01) 00626-3

127. Kampmann M., Boll S., Kossuch J., Bielecki J., Uhl S., Kleiner B., y otros. (2014). Inmovilización eficiente de la tirosinasa de hongos utilizando células enteras de Agaricus bisporus y su aplicación para la degradación del bisfenol A. Water Res. 57 295-303. 10.1016 / j.watres.2014.03.054 [ PubMed ]

128. Rama R., Mougin C., Boyer FD, Kollmann A., Malosse C., Sigoillot JC (1998). Biotransformación de benzo [a] pireno en un reactor a escala de banco utilizando lacasa de Pycnoporus cinnabarinus - Biotecnol. Letón. 20 1101-1104. 10.1023 / A: 1005387016390

129. Hofrichter M., Vares K., Scheibner K., Galkin S., Sipila J., Hatakka A. (1999). Mineralización y solubilización de lignina sintética por las peroxidasas de manganeso de Nematoloma frowardii y Phlebia radiata . J. Biotechnol. 67 217-228. 10.1016 / S01681656 (98) 00180-1

130. Kunz A., Reginatto V., Durán N. (2001). Tratamiento combinado de efluentes textiles utilizando la secuencia Phanerochaete chrysosporium-ozone. Quemosfera 44 281-287. 10.1016 / S0045-6535 (00) 00165-X [ PubMed ]

131. Pendyala B., Chaganti S. R., Lalman J. A., Heath D. D. (2016). Optimizing the performance of microbial fuel cells fed a combination of different synthetic organic fractions in municipal solid waste. Wast Manag. 49 73-82. 10.1016/j.wasman.2015.12.032 [PubMed] [Cross Ref]

132. Simpson DR (2008). Procesos de biopelículas en la purificación de agua con carbón biológicamente activo. Agua res. 42 2839-2848. 10.1016 / j.watres.2008.02.025 [ PubMed ]

133. Brown J., Lauderdale C. (2006). Destrucción eficiente y simultánea de múltiples contaminantes del agua potable mediante filtración biológica. Agua de Florida. J. 3 28-30.

134. Philip S., Keshavarz T., Roy I. (2007). Polyhydroxyalkanoates: biodegradable polymers with a range of applications. J. Chem. Technol. Biotechnol. 82 233-247. 10.1002/jctb.1667 [Cross Ref]

135. Figueiredo TVB, Campos MI, Sousa LS, Silva JR, Druzian JI (2014). Producción y distribución de polihidroxialcanoatos obtenidos por fermentación de glicerina residual de biodiesel. Quím. Nova 37 11111117. 10.5935 / 0100-4042.20140183

136. Mohanty AK, Misra M., Hinrichsen G. (2000). Biofibras, polímeros biodegradables y biocompuestos: una visión general. Macromol. Mater. Ing. 276277 1-24. 10.1002 / (SICI) 1439-2054 (20000301) 276: 1

137. Boyer LR, Feng W., Gulbis N., Hadju K., Harrison RJ, Jeffries P., y otros. (2016). El uso de hongos micorrízicos arbusculares para mejorar la producción de fresas en el sustrato de fibra de coco. Frente. Planta sci. 7 : 123710.3389 / fpls.2016.01237 [ Artículo libre de PMC ] [ PubMed ]

138. Gabriele M., Gerardi C., Longo V., Lucejko J., Degano I., Pucci L., et al. (2016). El impacto de los hongos micorrízicos en la producción de vino tin- 
to Sangiovese : compuestos fenólicos y propiedades antioxidantes. LWT Food Sci. Tecnol. 72 310-316. 10.1016 / j.lwt.2016.04.044

139. Köhl L., Lukasiewicz CE, van der Heijden MGA (2016). Establecimiento y efectividad de hongos micorrízicos arbusculares inoculados en suelos agrícolas. Medio ambiente de células vegetales. 39 136-146. $10.1111 /$ pce. 12600 [ PubMed ]

140. Smith SE, Read D. (2008). Simbiosis micorrícica 3ra ed. San Diego, CA: Academic Press.

141. Lanfranco L., Bonfante P., Género A. (2016). La interacción mutualista entre plantas y hongos micorrízicos arbusculares. Microbiol. Espectr. 4 : FUNK0012-2016 10.1128 / microbiolspec.FUNK-00122016 [ PubMed ]

142. Rillig MC, MA Sosa-Hernández, Roy J., Aguilar-Trigueros CA, Vályi K., Lehmann A. (2016). Hacia una tecnología integrada de las micorrizas: aprovechando las micorrizas para una intensificación sostenible en la agricultura. Frente. Planta sci. 7 : 162510.3389 / fpls.2016.01625 [ Artículo libre de PMC ] [ PubMed ]

143. Walker T., Johnson PH, Moreira LA, Iturbe-Ormaetxe I., Frentiu FD, McMeniman CJ, et al. (2011). La variedad wMel Wolbachia bloquea el dengue e invade las poblaciones enjauladas de Aedes aegypti . Naturaleza 476 450-453. 10.1038 / nature10355 [ PubMed ]

144. Cook PE, McMeniman CJ, O'Neill SL (2008). Modificación de la estructura de edad de la población de insectos para controlar enfermedades transmitidas por vectores. Adv. Exp. Medicina. Biol. 627 126-140. 10.1007 / 978-0-387-78225-6-11 [ PubMed]

145. Turley AP, Moreira LA, O’Neill S., McGraw EA (2009). La infección por Wolbachia reduce el éxito de la alimentación de sangre en el mosquito de la fiebre del dengue, Aedes aegypti . PLoS Negl. Trop. Dis. 3 : e516 10.1371 / journal.pntd.0000516 [ Artículo libre de PMC ] [ PubMed ]

146. Bian G., Xu Y., Lu P., Xie Y., Xi Z. (2010). La bacteria endosimbiótica Wolbachia induce resistencia al virus del dengue en Aedes aegypti . PLoS Pathog. 6 : e1000833 10.1371 / journal.ppat.1000833 [ Artículo libre de PMC ] [ PubMed ]

147. McMeniman CJ, Lane RV, Cass BN, Fong AWC, Sidhu M., Wang Y.-F., y otros. (2009). Introducción estable de una infección por Wolbachia que acorta la vida en el mosquito Aedes aegypti. Science 323 141-144. 10.1126/ science.1165326 [ PubMed]

148. Gill SS, Cowles EA, Pietrantonio PV (1992). El modo de acción de las endotoxinas de Bacillus thuringiensis . Annu. Rev. Entomol. 37 615-636. 10.1146/ annurev.en.37.010192.003151 [ PubMed ]

149. Mohiddin A., Lasim AM, Zuharah WF (2016). Susceptibilidad de Aedes albopictus desde áreas de brotes de dengue a temephos y Bacillus thuringiensis subsp. israelensis. Asia Pac. J. Trop. Biomed. $6295-$ 300. 10.1016 / j.apjtb.2016.01.006

150. Setha T., Chantha N., Benjamin S., Socheat D. (2016). Bacterial larvicide, Bacillus thuringiensis israelensis strain AM 65-52 water dispersible granule formulation impacts both dengue vector, Aedes aegypti (L.) population density and disease transmission in Cambodia. PLoS Negl. Trop. Dis. 10:e0004973 10.1371/journal.pntd.0004973 [PMC free article] [PubMed] [Cross Ref]

151. Castañeda, E., Sánchez, L. Evaluación del crecimiento de cuatro especies del género Bacillus sp., primer paso para entender su efecto biocontrolador sobre Fusarium sp. NOVA. 2016; 14 (26): 53-65

152. Paris M., Tetreau G., Laurent F., Lelu M., Despres L., David J.-P. (2011). Persistence of Bacillus thuringiensis israelensis (Bti) in the environment induces resistance to multiple Bti toxins in mosquitoes. Pest Manag. Sci. 67 122-128. 10.1002/ps.2046 [PubMed] [Cross Ref]

153. Paris M., Melodelima C., Coissac E., Tetreau G., Reynaud S., David J.-P., et al. (2012). Transcription profiling of resistance to Bti toxins in the mosquito Aedes aegypti using next-generation sequen- 
cing. J. Invertebr. Pathol. 109 201-208. 10.1016/j. jip.2011.11.004 [PubMed] [Cross Ref]

154. Wu S., Wu W., Zhu X., Liu Z., Rebeca C.-L., Fu T., y col. (2016). Respuesta fisiológica y bioquímica de la tolerancia de Aedes aegypti a Bacillus thuringiensis . Biocontrol Sci. Tecnol. 26 227-238. 10.1080 / 09583157.2015 .1089216

155. Durbin AP (2016). Una vacuna contra el dengue. Cell 1661 10.1016 / j.cell.2016.06.036 [ PubMed ]

156. Pitisuttithum P., Bouckenooghe A. (2016). La primera vacuna autorizada contra el dengue: una herramienta importante para las estrategias preventivas integradas contra la infección por el virus del dengue. Experto Rev. Vacunas. 15 795-798. 10.1080 / 14760584.2016.1189331 [ PubMed]

157. Nabel GJ (2013). Diseñando las vacunas del mańana. N. Engl. J. Med. 368 551-560. 10.1056 / NEJMra1204186 [ Artículo libre de PMC ] [ PubMed ]

158. Bobbala S., Hook S. (2016). ¿Existe una formulación óptima y una estrategia de administración para vacunas de subunidades? Farmacéutico Res. 33 2078-2097. 10.1007 / s11095-016-1979-0 [ PubMed ]

159. Cutts FT, Franceschi S., Goldie S., Castellsague X., de Sanjose S., Garnett G., et al. (2007). Virus del papiloma humano y vacunas contra el VPH: una revisión. Toro. Organismo Mundial de la Salud. 85 719-726. 10.1590 / S0042-96862007000900018 [ Artículo libre de PMC ] [ PubMed ]

160. Reed SG, Bertholet S., Coler RN, Friede M. (2009). Nuevos horizontes en adyuvantes para el desarrollo de vacunas. Tendencias Immunol. 30 23-32. $10.1016 /$ j.it.2008.09.006 [ PubMed ]

161. Gillison ML, Chaturvedi AK, Lowy DR (2008). Vacunas profilácticas contra el VPH y la posible prevención de cánceres no cúrcicos en hombres y mujeres. Cáncer 113 3036-3046. 10.1002 / cncr.23764 [ PubMed ]

162. Roden R., Wu T.-C. (2006). ¿Cómo afectarán las vacunas contra el VPH al cáncer cervical? Nat. Rev.
Cancer 6 753-763. 10.1038 / nrc1973 [ Artículo libre de PMC ] [ PubMed ]

163. Astronomo RD, Burton DR (2010). Vacunas de hidratos de carbono: ¿desarrollar soluciones dulces para situaciones pegajosas? Nat. Rev. Droga. Discov. 9 308-324. 10.1038 / nrd3012 [ Artículo libre de PMC ] [ PubMed ]

164. Pifferi C., Berthet N., Renaudet O. (2017). Cyclopeptide scaffolds in carbohydrate-based synthetic vaccines. Biomater. Sci. 5 953-965. 10.1039/C7BM00072C [PubMed] [Cross Ref]

165. Keitel WA, Bond NL, Zahradnik JM, Cramton TA, Robbins JB (1994). Respuestas clínicas y serológicas después de la inmunización primaria y de refuerzo con las vacunas de polisacáridos capsulares de Salmonella typhi Vi. Vacuna 12 195-199. 10.1016/ 0264-410X (94) 90194-5 [ PubMed ]

166. King WJ, MacDonald NE, Wells G., Huang J., Allen U., Chan F., y otros. (1996). Respuesta de anticuerpos total y funcional a una vacuna de polisacáridos meningocócicos cuadrivalentes en niños. J. Pediatr. 128 196-202. 10.1016 / S0022-3476 (96) 70389-X [ PubMed ]

167. Nishat S., Andreana PR (2016). Vacunas totalmente basadas en carbohidratos: un campo emergente para respuestas inmunes específicas y selectivas. Pharmaceutics 8710.3390 / pharmaceutics8010007 [ Artículo libre de PMC ] [ PubMed ]

168. Knuf M., Kowalzik F., Kieninger D. (2011). Efectos comparativos de las proteínas portadoras sobre la respuesta inmunológica inducida por la vacuna. Vacuna 29 4881-4890. 10.1016 / j.vaccine.2011.04.053 [ PubMed]

169. Frenck RW, Yeh S. (2012). El desarrollo de la vacuna antineumocócica conjugada 13-valente y su posible uso en adultos. Opinión de los expertos. Biol. El r. 12 63-77. 10.1517 / 14712598.2012.636348 [ PubMed ]

170. Pichichero M. E. (2013). Protein carriers of conjugate vaccines: characteristics, development, and 
clinical trials. Hum. Vaccin. Immunother. $92505-$ 2523. 10.4161/hv.26109 [PMC free article] [PubMed] [Cross Ref]

171. Robinson HL (1997). Vacunas de ácido nucleico: una visión general. Vacuna 15 785-787. 10.1016 / S0264-410X (96) 00249-6 [ PubMed ]

172. Brouillette M., Doré M., Hébert C., Spooner M.-F., Marchand S., Côté J., et al. (2016). Un nuevo inyector intradérmico biolístico. Ondas de choque 26 25-37. 10.1007 / s00193-013-0464-5

173. Fynan EF, Wwbster RG, Fuller DH, Haynes JR, Santoro JC, Robinson HL (1993). Vacunas de ADN: inmunizaciones protectoras por inoculación parenteral, mucosa y de pistola génica. Proc. Natl Acad Sci. USA 90 11478-11482. 10.1073 / pnas.90.24.11478 [ Artículo libre de PMC ] [ PubMed ]

174. Rao SS, Gómez P., Mascola JR, Dang V., Krivulka GR, Yu F., y otros. (2006). Evaluación comparativa de tres métodos de administración intramuscular diferentes para la inmunización con ADN en un modelo animal de primate no humano. Vacuna 24 367-373. 10.1016/ j.vaccine.2005.07.072 [ PubMed ]

175. Becker PD, Noerder M., Guzmán CA (2008). Inmunización genética: bacterias como vehículos de entrega de vacunas de ADN. Tararear. Vacunar 4 189-202. 10.4161/ hv.4.3.6314 [ PubMed ]

176. He Z., Wlazlo AP, Kowalczyk DW, Cheng J., Xiang ZQ, Giles-Daves W., et al. (2000). Vacunas virales recombinantes contra los antígenos E6 y E7 de HPV-16. Virología 270 146-161. 10.1006 / viro.2000.0271 [ PubMed ]

177. Carter PJ (2006). Potentes terapias de anticuerpos por diseńo. Nat. Rev. Immunol. 6 343-357. 10.1038 / nri1837 [ PubMed]

178. Corrales, L., Caycedo, L., Gómez, M., Ramos, S., Rodríguez, J. Bacillus spp: una alternativa para la promoción vegetal por dos caminos enzimáticos. NOVA. 2017; 15 (27): 45 - 65

179. Marasco W. A., Sui J. (2007). The growth and potential of human antiviral monoclonal antibody therapeutics. Nat. Biotechnol. 25 1421-1434. 10.1038/nbt1363 [PubMed] [Cross Ref]

180. El grupo de estudio IMpact-RSV (1998). Palivizumab, un anticuerpo monoclonal del virus sincicial respiratorio humanizado, reduce la hospitalización por infección del virus sincitial respiratorio en bebés de alto riesgo. Pediatría 102310.1542 / peds.102.3.531 [ PubMed ]

181. Kummerfeldt CE (2014). Raxibacumab para el tratamiento del ántrax por inhalación. Infectar. Resistencia a las drogas. 7 101-109. 10.2147 / IDR. S47305 [ Artículo libre de PMC ] [ PubMed ]

182. Baldo BA (2016). "Otros anticuerpos monoclonales terapéuticos aprobados”, en Safety of Biologics Therapy (Ciudad de Nueva York, NY: Springer International Publishing;) 141-215. 10.1007 / 978-3319-30472-4_4

183. Bajaj M., Schmidt S., Winter J. (2012). Formación de nanopartículas de Se (0) por Duganella sp. y Agrobacterium sp. aislado del suelo cargado de Se del Noreste de Punjab, India. Microbios Hecho de la célula. 11 : 64 10.1186/ 1475-2859-11-64 [ Artículo libre de PMC ] [ PubMed ]

184. Avendaño R., Chaves N., Fuentes P., Sánchez E., Jiménez JI, Chavarría M. (2016). Producción de nanopartículas de selenio en Pseudomonas putida KT2440. Sci. Rep. 63715510.1038 / srep37155 [ Artículo libre de PMC ] [ PubMed ]

185. Borghesi A., Stronati M. (2015). Superbugs y antibióticos en el recién nacido. J. Pediatr. Neonat Individuo Medicina. 4 : e040253 10.7363 / 040253

186. Vázquez E., Villaverde A. (2013). Biofabricación microbiana para nanomedicina: biomateriales, nanopartículas y más. Nanomedicina 8 1895-1898. 10.2217 / nnm.13.164 [ PubMed ]

187. Rodriguez-Carmona E., Villaverde A. (2010). Nanostructured bacterial materials for innovative medicines. Trends Microbiol. 18 423-430. 10.1016/j. tim.2010.06.007 [PubMed] [Cross Ref] 
188. Nizet V. (2015). Deteniendo las superbacterias, manteniendo la microbiota. Sci. Transl. Medicina. 7 295ed8 10.1126/scitranslmed.aab2373 [ PubMed]

189. Brito MA, Cordeiro BC (2012). La necesidad de nuevos antibióticos. J. Bras. Patol. Medicina. Laboratorio. 48 247-249. 10.1590 / S167624442012000400002

190. Chumnanpuen P., Kocharin K., Vongsangnak W. (2016). "Sistemas de expresión de levadura para biotecnología industrial”, en Sistemas de expresión génica en hongos: avances y aplicaciones, parte de la serie Fungal Biology eds Schmoll M., Dattenböck C., editores. (Ciudad de Nueva York, NY: Springer International Publishing;) 227-237. 10.1007 / 9783-319-27951-0-9

191. Sanchez-Garcia L., Martín L., Mangues R., Ferrer-Miralles N., Vázquez E., Villaverde A. (2016). Recombinant pharmaceuticals from microbial cells: a 2015 update. Microb. Cell Fact. 1533 10.1186/ s12934-016-0437-3 [PMC free article] [PubMed] [Cross Ref]

192. Ferrer-Miralles N., Domingo-Espín J., Corchero JL, Vázquez E., Villaverde A. (2009). Fábricas de microbios para productos farmacéuticos recombinantes. Microbios Hecho de la célula. 8 : 17 10.1186 / 14752859-8-17 [ Artículo libre de PMC ] [ PubMed ]

193. Borghese R., Brucale M., Fortunato G., Lanzi M., Mezzi A., Valle F., et al. (2016). Producción extracelular de nanopartículas de teluro por la bacteria fotosintética Rhodobacter capsulatus . J. Hazard. Mater. 309 202-209. 10.1016 / j.jhazmat.2016.02.011 [ PubMed ]

194. Overton T. W. (2014). Recombinant protein production in bacterial hosts. Drug Discov. Today 19 590-601. 10.1016/j.drudis.2013.11.008 [PubMed] [Cross Ref]

195. Zhang X., Tervo CJ, Reed JL (2016). Evaluación metabólica de E. coli como biofábrica para productos comerciales. Metab. Ing. 35 64-74. 10.1016 / j.ymben.2016.01.007 [ PubMed]
196. Olmos-Soto J., Contreras-Flores R. (2003). Genetic system constructed to overproduce and secrete proinsulin in Bacillus subtilis. Appl. Microbiol. Biotechnol. 62 369-373. 10.1007/s00253-003-1289-4 [PubMed] [Cross Ref]

197. Sandgathe A., Tippe D., Dilsen S., Meens J., Halfar M., Weuster-Botz D., et al. (2003). Production of a human calcitonin precursor with Staphylococcus carnosus: secretory expression and single-step recovery by expanded bed adsorption. Process Biochem. 38 1351-1363. 10.1016/S0032-9592(02)00332-1 [Cross Ref]

198. Liu K., Ding X., Deng B., Chen W. (2009). Aislamiento y caracterización de hongos endófitos productores de taxol de Taxus chinensis. J. Ind. Microbiol. Biotecnol. 36 1171-1177. 10.1007 / s10295-009-0598-8 [ PubMed ]

199. Cano-Garrido O., Céspedes MV, Unzueta U., Saccardo P., Roldán M., Sánchez-Chardi A., et al. (2016). Nanopartículas de proteínas dirigidas a CXCR 4 + producidas en la bacteria de grado alimenticio Lactococcus lactis . Nanomedicina 11 23872398. 10.2217/ nnm-2016-0200 [ PubMed]

200. Paterson R. R. M. (2006). Ganoderma-A therapeutic fungal biofactory. Phytochemistry $671985-$ 2001. 10.1016/j.phytochem.2006.07.004 [PubMed] [Cross Ref]

201. Paterson R. R. M. (2008). Cordyceps-A traditional Chinese medicine and another fungal therapeutic biofactory? Phytochemistry 69 1469-1495. 10.1016/j.phytochem.2008.01.027 [PubMed] [Cross Ref]

202. Wadt NSY, Okamoto MKH, Bach EM, Bach EE (2015). Evaluación química, toxicológica, antiinflamatoria y antimicrobiana de extractos de Ganoderma lucidum . Emir. J. Food Agric. 27 577-584. 10.9755 / ejfa.2015.05.309

203. Gangadevi V., Muthumary J. (2008). Aislamiento de Colletotrichum gloeosporioides, un nuevo hongo endófito productor de taxol de las hojas de una planta medicinal, Justicia gendarussa . Mycol. Balc. 
$51-4$.

204. Luengo JM, García B., Sandoval A., Naharro G., Oliveira ER (2003). Bioplásticos procedentes de microorganismos. Curr. Opin. Microbiol. 6 251-260. 10.1016 / S1369-5274 (03) 00040-7 [ PubMed ]

205. Ivanov V., Stabnikov V. (2016). "Plásticos biotecnológicos de construcción”, en Biotecnología de la construcción, parte de la serie Green Energy and Technology (Singapur: Springer;) 51-75. 10.1007 / 978-981-10-1445-1_4

206. Khor E., Lim LY (2003). Aplicaciones implantables de quitina y quitosano. Biomateriales 24 23392349. 10.1016 / S0142-9612 (03) 00026-7 [ PubMed ]

207. Accinelli C., Abbas HK, Little NS, Kotowicz JK, Mencarelli M., Shier WT (2016). Una formulación líquida bioplástica para recubrimiento de película de semillas agronómicas. Crop Prot. 89 123-128. 10.1016 / j.foodhyd.2016.10.001

208. Pires ALR, Moraes AM (2015). Mejora de las propiedades mecánicas de los apósitos para heridas de algitosato de quitosano que contienen plata mediante la adición de un caucho de silicona biocompatible. J. Appl. Polym Sci. 132 : 4168610.1002 / APP.41686

209. Bejenariu A., Popa M., Cerf DL, Picton L. (2008). Rigidez de los hidrogeles de xantano: síntesis, características de hinchamiento y propiedades de liberación controlada. Polym Toro. 61 631-641. 10.1007 / s00289-008-0987-6

210. Barua R., Alam MJ, Salim M., Ashrafee TS (2016). Producción y caracterización a pequeña escala de goma xantana sintetizada por aislamientos locales de Xanthomonas campestris . Indian J. Exp. Biol. 54 151-155. [ PubMed ]

211. Velu S., Velayutham V., Manickkam S. (2016). Optimización de los medios de fermentación para la producción de goma xantana de Xanthomonas campestris utilizando la metodología de superficie de respuesta y técnicas de redes neuronales artificiales. Indian J. Chem. Tecnol. 23 353-361.
212. Ruholahi F., Mohammadi M., Karimi K., Zamani A. (2016). Nickel biosorption by fungal chitosan from Mucor Indicus. J. Chitin. Chitosan. 4 69-73. 10.1166/jcc.2016.1102 [Cross Ref]

213. Abdel-Gawad KM, Hifney AF, MA Fawzy, Gomaa M. (2017). Optimización tecnológica de la producción de quitosán a partir de biomasa de Aspergillus niger y sus actividades funcionales. Comida Hydrocoll. 63 593-601. 10.1016 / j.foodhyd.2016.10.001

214. Tayel AA, Gharieb MM, Zaki HR, Elguindy NM (2016b). Bio-clarificación de agua de metales pesados y efluencia microbiana utilizando quitosano fúngico. En t. J. Biol. Macromol. 83 277-281. 10.1016 / j.ijbiomac.2015.11.072 [ PubMed]

215. Hay ID, Rehman ZU, Moradali MF, Wang Y., Rehm BHA (2013). Producción de alginato microbiano, modificación y sus aplicaciones. Microbios Biotecnol. 6 637-650. 10.1111/1751-7915.12076 [ Artículo libre de PMC ] [ PubMed ]

216. Maleki S., Almaas E., Zotchev S., Valla S., Ertesvåg H. (2016). Alginate biosynthesis factories in Pseudomonas fluorescens: localization and correlation with alginate production level. Appl. Environ. Microbiol. 82 41227-41236. 10.1128/AEM.0311415 [PMC free article] [PubMed] [Cross Ref]

217. Lee KY, Mooney DJ (2012). Alginato: propiedades y aplicaciones biomédicas. Prog. Polym Sci. 37 106-126. 10.1016 / j.progpolymsci.2011.06.003 [ Artículo libre de PMC ] [ PubMed ]

218. Su L., Jia W., Hou C., Lei Y. (2011). Biosensores microbianos: una revisión. Biosens. Bioelectron. 26 1788-1799. 10.1016 / j.bios.2010.09.005 [ PubMed ]

219. D'Souza SF (2001). Biosensores microbianos. Biosens. Bioelectron. 16 337-353. 10.1016 / S09565663 (01) 00125-7 [ PubMed] 49

220. Paitan Y., Biran D., Biran I., Shechter N., Babai R., Rishpon J., et al. (2003). On-line and in situ biosensors for monitoring environmental pollution. Biotechnol. Adv. 22 27-33. 10.1016/j.biote- 
chadv.2003.08.014 [PubMed] [Cross Ref]

221. Lei Y., Chen W., Mulchandani A. (2006). Biosensores microbianos. Anal. Chim Acta 568 200210. 10.1016 / j.aca.2005.11.065 [ PubMed ]

222. Bechor O., Smulski DR, Van Dyk TK, LaRossa RA, Belkin S. (2002). Microorganismos recombinantes como biosensores ambientales: detección de contaminantes por Escherichia coli con fusiones fabA ' :: lux. J. Biotechnol. 94 125-132. 10.1016 / S01681656 (01) 00423-0 [ PubMed ]

223. Mulchandani A., Mulchandani P., Kaneva I., Chen W. (1998). Biosensor para la determinación directa de agentes nerviosos organofosforados utilizando Escherichia coli recombinante con organofosforosa hidrolasa expresada en la superficie. 1. Electrodo potenciométrico microbiano. Anal. Chem. 70 4140-4145. 10.1021 / ac9805201 [PubMed]

224. Kim HJ, Lim JW, Jeong H., Lee S.-J., Lee D.-W., Kim T., et al. (2016). Desarrollo de un biosensor microbiano de plomo y cadmio altamente específico y sensible utilizando un circuito genético sintético CadC-T7. Biosens. Bioelectron. 79 701-708. 10.1016/ j.bios.2015.12.101 [ PubMed ]

225. Kim KR, Song YH, Seo JH, Kang DG (2016). Efecto de las condiciones de cultivo sobre la actividad celular completa de Escherichia coli recombinante que expresa la hidrolasa organofosforosa periplásmica y la chaperona GroEL / ES citosólica. Biotecnología . Bioprocesos ing. 21 502-507. 10.1007 / s12257016-0342-y

226. Shin H. J. A. (2016). Recombinant microbial biosensor for cadmium and lead detection. J. Life Sci. 26 503-508. 10.5352/JLS.2016.26.5.503 [Cross Ref]

227. Bharadwaj S., Mitchell RJ, Qureshi A., Niazi JH (2017). Evaluación de la toxicidad del jugo electrónico y sus aerosoles solubles generados por los cigarrillos electrónicos que utilizan bacterias bioluminiscentes recombinantes que responden a dańos celulares específicos. Biosens. Bioelectron. 90 53-60. 10.1016 / j.bios.2016.11.026 [ PubMed ]
228. Rasinger JD, Marrazza G., Briganti F., Scozzafava A., Mascini M., Turner APF (2005). Evaluación de un biosensor amperométrico bacteriano operado por FIA, basado en Pseudomonas putida F1 para la detección de benceno, tolueno, etilbenceno y xilenos (BTEX). Anal. Letón. 38 1531-1547. 10.1081 / AL200065793

229. Timur S., Haghighi B., Tkac J., Pazarhoglu N., Telefoncu A., Gorton L. (2007). Cableado eléctrico de Pseudomonas putida y Pseudomonas fluorescens con polímeros redox de osmio. Bioelectroquímica 71 38-45. $10.1016 /$ j.bioelechem.2006.08.001 [ PubMed ]

230. Banik RM, Mayank Prakash R., Upadhyay SN (2008). Biosensor microbiano basado en células completas de Pseudomonas sp. Para la medición en línea de p-nitrofenol. Sens. Actuatators B Chem. 131 295300. $10.1016 /$ j.snb.2007.11.022

231. Stoytcheva M., Zlatev R., Magnin J.-P., Ovalle M., Valdez B. (2009). Leptospirillum ferrooxidans baseadora Fe 2+ sensor. Biosens. Bioelectron. 25 482-487. 10.1016 / j.bios.2009.08.019 [ PubMed]

232. Zlatev R., Magnin J.-P., Ozil P., Stoytcheva M. (2006). Sensores bacterianos basados en Acidithiobacillus ferrooxidans : parte I. Determinación de Fe 2+ y S 2 O 3 2- . Biosens. Bioelectron. 21 1493-1500. 10.1016 / j.bios.2005.07.007 [ PubMed ]

233. Katrlik J., Vostiar I., Sefcovicova J., Tkac J., Mastihuba V., Valach M., et al. (2007). Un nuevo biosensor microbiano basado en células de Gluconobacter oxydans para la determinación selectiva de 1,3-propanodiol en presencia de glicerol y su aplicación al monitoreo de bioprocesos. Anal. Bioanal Chem. 388 287-295. 10.1007 / s00216-007-1211-5 [ PubMed ]

234. Valach M., Katrlik J., Sturdik E., Gemeiner P. (2009). Biosensor de etanol Gluconobacter diseñado para análisis de inyección de flujo: aplicación en el monitoreo fuera de línea de fermentación de etanol. Sens. Actuadores B 138 581-586. 10.1016/ j.snb.2009.02.017 